\title{
Biochemical and molecular characterisation of exogenous cytokinin application on grain filling in rice
}

Binay Bhushan Panda', Sudhanshu Sekhar ${ }^{1}$, Sushant Kumar Dash², Lamboder Behera ${ }^{2}$ and Birendra Prasad Shaw ${ }^{1 *}$

\begin{abstract}
Background: Poor filling of grains in the basal spikelets of large size panicles bearing numerous spikelets has been a major limitation in attempts to increase the rice production to feed the world's increasing population.

Considering that biotechnological intervention could play important role in overcoming this limitation, the role of cytokinin in grain filling was investigated based on the information on cell proliferating potential of the hormone and reports of its high accumulation in immature seeds.
\end{abstract}

Results: A comparative study considering two rice varieties differing in panicle compactness, lax-panicle Upahar and compact-panicle OR-1918, revealed significant difference in grain filling, cytokinin oxidase (CKX) activity and expression, and expression of cell cycle regulators and cytokinin signaling components between the basal and apical spikelets of OR-1918, but not of Upahar. Exogenous application of cytokinin (6-Benzylaminopurine, BAP) to OR-1918 improved grain filling significantly, and this was accompanied by a significant decrease in expression and activity of CKX, particularly in the basal spikelets where the activity of CKX was significantly higher than that in the apical spikelets. Cytokinin application also resulted in significant increase in expression of cell cycle regulators like cyclin dependent kinases and cyclins in the basal spikelets that might be facilitating cell division in the endosperm cells by promoting G1/S phase and G2/M phase transition leading to improvement in grain filling. Expression studies of type-A response regulator (RR) component of cytokinin signaling indicated possible role of OsRR3, OsRR4 and OsRR6 as repressors of CKX expression, much needed for an increased accumulation of CK in cells. Furthermore, the observed effect of BAP might not be solely because of it, but also because of induced synthesis of trans-zeatin (tZ) and $\mathrm{N}^{6}$-( $\Delta^{2}$-isopentenyl)adenine (iP), as reflected from accumulation of tZR (tZ riboside) and iPR (iP riboside), and significantly enhanced expression of an isopentenyl transferase (IPT) isoform.

Conclusion: The results suggested that seed-specific overexpression of OsRR4 and OsRR6, and more importantly of IPT9 could be an effective biotechnological intervention towards improving the CK level of the developing caryopses leading to enhanced grain filling in rice cultivars bearing large panicles with numerous spikelets, and thereby increasing their yield potential.

Keywords: Cytokinin oxidase, Cytokinin treatment, 6-Benzylaminopurine, Cell cycle regulators, Chromosomal endoreduplication, Oryza sativa

\footnotetext{
* Correspondence: bpsils@ils.res.in; b_p_shaw@yahoo.com

${ }^{1}$ Institute of Life Sciences, Bhubaneswar, Odisha, India

Full list of author information is available at the end of the article
}

(c) The Author(s). 2018 Open Access This article is distributed under the terms of the Creative Commons Attribution 4.0 International License (http://creativecommons.org/licenses/by/4.0/), which permits unrestricted use, distribution, and reproduction in any medium, provided you give appropriate credit to the original author(s) and the source, provide a link to the Creative Commons license, and indicate if changes were made. The Creative Commons Public Domain Dedication waiver (http://creativecommons.org/publicdomain/zero/1.0/) applies to the data made available in this article, unless otherwise stated. 


\section{Background}

Rice is a staple crop for the people of Asian and African regions, which are most populated as well compared with other regions of the world [1]. Demand for cereal brought in green revolution in rice in the Asian countries in the last half of the twentieth century, mid 1960s to mid 1990s, doubling its worldwide production from $6 \mathrm{t} / \mathrm{ha}$ to $10 \mathrm{t} / \mathrm{ha}$ $[2,3]$. However, the rate of $2.7 \%$ increase in annual yield achieved in 1980s has got drastically reduced to $1.1 \%$ evaluated until 1990s [3]. This is in sharp contrast to the fact that the world population is going to increase to 9.6 billion by 2050 [4] from the current figure of 7.3 billion [5]. The rapid increase in world population coupled with economic development is putting increasing demand to increase food production [6], and according to one estimate, $56 \%$ more rice is required to be produced in next three decades to meet the demand [7].

The first green revolution was primarily the result of genetic improvement of the rice varieties, in addition to expansion of the land area under irrigation and judicious use of fertilizers and agro-chemicals $[3,8]$. The major genetic improvement was in terms of increase in yield potential because of the release of short-stature semi-dwarf genotypes of both the rice sub-species, Japonica and Indica, which increased the harvest index from 0.3 to 0.5 $[3,9]$. To increase the yield further, keeping in view the growing population of the world and narrowing down of the gap between yield potential and farmers' yield [10], the new plant type (NPT) was designed to increase the harvest index approximately to 0.6 by modifying the architecture of the plant, including the number of spikelets on the panicle [9]. The effort to increase the number of spikelets on panicles was made to enhance the sink capacity with the aim of breaking the yield ceiling. Breeding effort in this regard resulted in cultivars with large panicles bearing numerous spikelets, including the NPT of the International Rice Research Institute (IRRI) [10] and 'super hybrid rice' in China $[11,12]$. The yield potential of these cultivars is, however, not harnessed due to poor filling and maturation of grains in the spikelets, particularly of those occupying inferior (basal) position on the panicle $[10,13$, 14]. Poor filling of grains is also seen in the spikelets of other large panicle rice varieties/cultivars $[15,16]$.

Apart from seed setting, the grain yield in rice to a great extent is thus determined by the numbers of spikelets borne on the panicles, which in itself is a quantitative trait [17]. So far 17 QTLs have been identified that determines the number of spikelets on rice panicles [17]. Panicle development is a transition from vegetative to reproductive phase wherein the shoot apical meristem is transformed into panicle meristem that differentiates into primary, secondary, or even tertiary lateral meristems producing primary, secondary and tertiary branches, respectively, with each lateral meristem terminating into a spikelet/floret
$[17,18]$. The factors determining the size of panicle or inflorescence and the number of spikelets on it are largely unknown. However, one of the most effective QTLs identified and cloned for grain number is Gn1a encoding cytokinin oxidase/dehydrogenase (OsCKX2) that degrades cytokinins [19]. The loss of function mutation of Gnla (OsCKX2) was also demonstrated to be the reason for a greater number of spikelets in the cultivar compared with that having functional OsCKX2 [19]. Gn1a has also been recently demonstrated as a negative regulator of grain number by mutating the gene using CRISPR/Cas9 gene editing technique, which resulted in significant increase in number of flowers (spikelets) per panicle in the mutant lines of Zhonghua 11 Japonica caultivar [20]. In addition, mutations of the genes like DEP1 (DENSE AND ERECT PANICLE1) and IPA1 (IDEAL PLANT ARCHITECTURE1) that control panicle architecture and tillering, respectively, by CRISPR/Cas9 editing also led to increase in the number of spikelets per panicle, suggesting pleotropic effects of the yield related genes [20].

Considering the fact that auxin inhibits axillary bud growth, while cytokinin relieves the growth inhibition $[17,21]$, a greater number of spikelets in the cultivar having non-functional OsCKX2 compared with that having functional OsCKX2 [19] is plausible. In addition to promoting axillary buds growth, the plant hormone cytokinin is known for its regulation of many cellular and developmental processes, such as induction of cell division and de novo shoot formation [22], flowers and fruit development, and seed germination [23], shoot and root branching [24], photomorphogenic development and vascular differentiation $[25,26]$, and chloroplast biogenesis and leaf senescence [27]. In these contexts, the role of OsCKX becomes very important because it could regulate the level of the hormone cytokinins in cells and tissues, as is evident from decrease/increase in cytokinin contents in CKX overexpressing/knockdown plants [28, 29], in addition to regulation of the cellular levels of the hormone by biosynthetic processes and conversion to functionally inactive forms through $\mathrm{N}$ - and O-glycosylation [30, 31].

In addition to panicle development, important role of cytokinin and other plant hormones has also been indicated in development of a spikelet to a mature grain after fertilization. The process of grain development includes increase in endosperm cell numbers and filling of the endosperm cells with starch. Both these processes are slow in the basal than that in the apical spikelets of large panicle rice, resulting in a poor filling of grains in the former. However, spikelet-thinning treatment by removing some of the apical spikelets, which increased filling of grains in the basal spikelets, has proved it sufficiently that each spikelet is competent to get filled well post-fertilization producing well-developed grain [32,33]. This proves beyond doubt that it is not the supply of carbohydrates or 
the source, but the sink strength, the product of sink size and sink activity, that limits the grain filling process and ultimately grain development by putting physiological constrain on the import of assimilates [34]. However, the intrinsic factor(s) causing differential grain filling in rice spikelets based on their spatial location is by and large still illusive. Reports of inhibition of grain filling by ethylene and its promotion by abscisic acid (ABA) and auxin in the basal spikelets $[35,36]$, nevertheless, indicate a possible role of plant hormones in differential grain filling in the apical and basal spikelets. Furthermore, Yang et al. [37] have indicated that both $\mathrm{ABA}$ and ethylene are required for post-fertilization growth of ovule into grain, but a high ABA to ethylene ratio in the spikelets leads to a faster rate of grain filling. There are also reports of involvement of gibberellins and ABA in regulation of grain development $[38,39]$. Keeping in view the role of cytokinin in promoting cell division, and the finding that generally a high level of cytokinin is maintained in the endosperm during seed development, it has been suggested that action of the hormone might be essential to promote endosperm cell division that is required during the initial period of the seed development process $[40,41]$. Studies have also found that the cytokinin level in spikelets significantly increases with seed development in wheat, rice and maize [35, 42-45].

Despite a clear indication of regulatory role of plant hormones, particularly of cytokinin, in seed development, a clear understanding on mechanistic details of the hormone action in the process is not yet fully delineated. In the present study the objectives were to understand the involvement and role of cytokinin in grain filling by conducting a comparative study of activities and expression of cytokinin oxidase (CKX), expression of cytokinin signaling components and other grain filling related parameters in the apical and basal spikelets of rice varieties/cultivars that differed in grain filling in the spikelets borne on the basal region of panicle, and to see the influence of external application of cytokinin on the grain filling process in the cultivar showing differential grain filling in the apical and basal spikelets.

\section{Methods}

\section{Rice cultivars and cytokinin application}

Based on our previous experience of grain filling in various Indica rice (Oryza sativa L.) cultivars [15, 16], two of them, Upahar and OR-1918 that showed good and poor grain filling, respectively were selected for the present study. Seeds of these plants were collected from OUAT (Orissa University of Agriculture and Technology), Bhubaneswar, India. The seeds were germinated and grown on nursery bed, and almost 30 days old seedlings were transplanted during Kharif season of 2015. For the comparative study of yield parameters and enzyme activity, the seedlings of the two cultivars were transplanted in the field facility at National
Rice Research Institute (NRRI). Plantation was done in $3 \times 3 \mathrm{~m}$ split design plots with three replicates. The plantation was done at $20 \times 15 \mathrm{~cm}$ spacing. Chemical fertilizers in the form of urea $(\mathrm{N})$ muriate of potash $(\mathrm{K})$ and single superphosphate $(\mathrm{P})$ were applied at the rate $80(\mathrm{~N}): 40(\mathrm{~K})$ : $40(\mathrm{P}) \mathrm{kg} \mathrm{ha}^{-1}$ in split doses; $50 \%$ of $\mathrm{N}$ and $\mathrm{K}$, and all of $\mathrm{P}$ during transplantation, $25 \%$ of $\mathrm{N}$ during tillering and the remaining $25 \%$ of $\mathrm{N}$ and half of $\mathrm{K}$ during panicle initiation stage. The water level in the field was maintained $\sim 6 \mathrm{~cm}$ throughout before maturity.

For the study of effect of cytokinin on grain filling, panicle morphology and various biochemical parameters, only the rice cultivar OR-1918 was considered. The seedlings grown as above were transplanted into experimental pots in the Rabi season (2016). The pots were circular made of 1.25 " thick RCC structure measuring 42 " in diameter and 23 " in depth. Ten pots were placed in two lanes in open place in the Institute's campus avoiding any shadow. These were filled with a mixture of sandy loam soil and farmyard manure (3:1) leaving $\sim 6$ " space from top and watered till the soil got inundated. The volume of water required to fill the individual pots completely, leaving 3 " space from top, was recorded. Water in the individual pots was allowed to evaporate until the soil was just wet. At this point each pot was filled with $\sim 2$ " of water above the soil and 9 seedlings were transplanted at the rate one seedling per square foot. The pots were irrigated with water regularly maintaining the water level of the individual pots $\sim 3$ " from top all the time. Commercially available fertilizers containing $\mathrm{N}, \mathrm{K}$ and $\mathrm{P}$ were applied as above. Synthetic cytokinin BAP (6-Benzylaminopurine) was applied exogenousely for uptake by root. The hormone was applied to one of the rows of the pots to a final concentration of $50 \mu \mathrm{M}$ at the late booting stage, i.e. just before emergence of the inflorescence, taking into consideration the total volume of water in each pot. BAP treatment concentration of $50 \mu \mathrm{M}$ was considered based on earlier report of use of such concetration of the hormone for exogenous application [46].

\section{Spikelet sampling and yield parameters study}

Sampling of the spikelets for various analyses was based on their anthesis period. In rice, anthesis starts from apical region of the panicle and progress towards the basal region, getting completed in about 6 days. The spikelets occupying the primary branches at the apical region reach anthesis first. It takes approximately 3 days for the spikelets on the middle of the panicle to reach anthesis. The day on which the anthesis begins either on the apical or basal part of the panicle was referred ' 0 ' day after anthesis (DAA). The main shoot and the primary tillers were marked with colour threads on the day on which they showed emergence of panicle and the spikelets on the top primary branches in the apical region showed 
anthesis. The spikelets from the apical and basal regions of the panicle were excised on their respective 3, 6, 9 and 12 days post anthesis, and these were referred as 3, 6, 9 and 12 DAA samples, respectively. The samples collected in replicates in $15 \mathrm{~mL}$ falcon tubes were dipped in liquid nitrogen immediately and stored at $-80{ }^{\circ} \mathrm{C}$ until use. The main tillers and the primary branches not used for sampling of spikelets were allowed to progress to maturity for the study of yield parameters, which included panicle length, panicle weight, total grain numbers, percentage of filled grain, 20 apical grain weight, 20 basal grain weight and yield per plant.

\section{Cytokinin oxidase (CKX) activity}

Cytokinin oxidase activity was studied in the spikelets of Upahar and OR-1918 sampled on 3, 6, 9 and 12 DAA from the apical and basal regions of the panicle. The activity of the enzyme was estimated following Frébort et al. [47]. The frozen spikelet samples collected as above were crushed in liquid nitrogen separately using porcelain mortar and pestle. Three biological replicates were taken. The powdered tissue of the individual samples was suspended in the ezyme extraction solution made of $0.1 \mathrm{M}$ Tris- $\mathrm{HCl}$ buffer (pH 8.0), $1 \mathrm{mM}$ phenylmethylsulfonyl fluoride, 1\% protease inhibitor (Focus Protease Arrest ${ }^{\mathrm{si}}$, Cat. \#786108F, GBiosciences), $2 \mathrm{mM}$ dithiothreitool and 1\% Triton X-100 in 3:1 $(v / w)$ ratio in $2 \mathrm{~mL}$ microfuge tube and kept over ice for $30 \mathrm{~min}$ with gentle shaking several times. The tissue suspension was centrifuged for $10 \mathrm{~min}$ at $12000 \times \mathrm{g}$ to pellet out the cell debris. The supernatant was used for CKX activity assays. The enzymatic reaction for each biological sample extract was carried out in triplicate. Each enzymatic reaction mixture contained $100 \mu \mathrm{L}$ enzyme extract, $0.5 \mathrm{mM}$ DCPIP (2,6-dichlorophenol indophenol, an electron acceptor) and $0.15 \mathrm{mM}$ iP in a final volume of $0.6 \mathrm{~mL} 75 \mathrm{mM}$ Tris- $\mathrm{HCl}$ buffer ( $\mathrm{pH}$ 8.0). The substrate iP was added last and the mixture was incubated for $1 \mathrm{~h}$ at $37{ }^{\circ} \mathrm{C}$ for the enzymatic reaction to proceed. The progress of the reaction in the individual tubes was stopped by adding $0.3 \mathrm{~mL}$ of $40 \%(w / v)$ TCA (trichloroacetic acid). After $15 \mathrm{~min}$ the reaction mixture was centrifuged for $5 \mathrm{~min}$ at $12000 \times \mathrm{g}$ to remove the precipitate. The supernatant was collected and to it was added $0.2 \mathrm{~mL}$ of 4 -aminophenol $(2 \% \mathrm{w} / \mathrm{v}$ solution in 6\% TCA). After 5 min the reation solution was transferred in a quartz cuvette for measuring the absorbance at $352 \mathrm{~nm}$. The enzymatic degradation product 3-methyl-2butenal reacts with 4-aminophenol under acidic conditions to form Schiff base ((4-hydroxyphenylimino)-3-methyl-2buten) having a molar absorption co-efficient of $\varepsilon_{352}=15$. $2 \mathrm{mM}^{-1} \mathrm{~cm}^{-1}$. The enzyme activity was calculated considering the protein concentration of the enzyme extract and the Schiff base produced. Protein concentration in the individual enzyme extracts was determined using Bradford reagent [48].

\section{Gene expression studies}

Expression studies of all the genes under consideration were done by RT-PCR and RT-qPCR. Extraction of total RNA from the individual spikelet samples (stored at $-80{ }^{\circ} \mathrm{C}$ ) was done using TRIZOL (Thermo Fisher Scientific) as per the instruction manual. Pelleted RNA of the individual samples was dissolved in DEPC-water separately and the concentration of RNA in each was measured using a nano-drop spectrophotometer. The RNA extracted from each sample was stored at $-80{ }^{\circ} \mathrm{C}$ until used for the expression studies. QuantiTect Reverse Transcription Kit from Qiagen was used to reverse transcribe the RNA to cDNA following the kit's instruction manual. The individual cDNA preparations were used for gene expression studies. The cDNA sequence of the individual genes was extracted from the publically accessible websites of Rice Genome Project Annotation (http://rice. plantbiology.msu.edu/index.shtml), NCBI (http://www.nc bi.nlm.nih.gov), and EnsemblePlants (http://plants.ense mbl.org/index.html). The primers for the expression study of the individual genes were designed using primerBLAST software (http://www.ncbi.nlm.nih.gov/tools/primer-blast/) at the NCBI site (Additional file 1) considering the sequences retrieved from all the three sites. DNA engine (Bio-Rad) thermocycler was used for PCR. The reagents used were PCR nucleotide mix (Promega, C1141) and GoTaq ${ }^{\circ}$ DNA Polymerase (Promega, M8291). The programme set for each PCR was $94^{\circ} \mathrm{C}$ for $3 \mathrm{~min}, 30 \mathrm{cy}$ cles each of $94{ }^{\circ} \mathrm{C}$ for $1 \mathrm{~min}, 59^{\circ} \mathrm{C}$ for $1 \mathrm{~min}$ and $72{ }^{\circ} \mathrm{C}$ for $1 \mathrm{~min}$, and finally $72{ }^{\circ} \mathrm{C}$ for $10 \mathrm{~min}$ and then $4{ }^{\circ} \mathrm{C}$ were maintained. The PCR products were run on $2 \%$ agarose gel impregnated with ethidium bromide $\left(0.2 \mu \mathrm{g} \mathrm{mL} \mathrm{m}^{-1}\right.$ agarose solution) and visualized under UV illumination on a trans-illuminator. Actin served as the reference gene. Based on the results of RT-PCR, RT-qPCR was performed for the desired genes on LightCycler 480 Real-Time PCR System (Roche) using Brilliant III Ultra-Fast SYBR ${ }^{\circ}$ Green QPCR Master Mix (Agilent Technologies). The relative level of cDNA templates of the concerned gene was obtained following Pfaffl [49] and considering Actin cDNA templates as the reference level. The results were expressed as relative level $\left(2^{-\Delta \Delta C}{ }_{T}\right)$ in Apical/Basal spikelets or BAP treated/control spikelets with value less than one representing a lower expression in apical compared with basal or that in treated compared with control.

\section{Endosperm cell counting and flowcytometeric analysis}

The spikelets of 12 DAA apical and basal samples were kept submerged for $48 \mathrm{~h}$ in Carnoy's solution $(9: 3: 1 \mathrm{v} / \mathrm{v} / \mathrm{v}$ of absolute alcohol, glacial acetic acid and chloroform), and subsequently transferred to $70 \%$ ethanol diluted with water till further processing [50]. Following this, the hulls were removed and the caryopses were sequentially soaked in 50\% 
and $25 \%$ ethanol in water for $1 \mathrm{~h}$ each and finally soaked in Milli-Q water for 5-7 h. Subsequently, individual caryopses were placed in $1 \mathrm{~mL}$ solution of $0.1 \% \mathrm{w} / v$ cellulase (C1794 Sigma Aldrich), $\mathrm{pH} 5.0$, and incubated at $40{ }^{\circ} \mathrm{C}$ in an orbital shaker for 5-6 h at $250 \mathrm{rpm}$. The endosperm cells liberated were collected by passing the hydrolyzed materials through $150 \mu$ nylon mesh [51]. The endosperm cells liberated $(10 \mu \mathrm{L})$ from the individual caryopses were transferred in Delafield's haematoxylin solution and kept for $30 \mathrm{~h}$ for staining. The stained cells were centrifuged out and then suspended in Milli-Q water and centrifuged several times at $150 \mathrm{x}$ g to remove the excess stain. The stained cells were finally pelleted out and suspended in $100 \mu \mathrm{L}$ Milli-Q water. An aliquot of each cell suspension was then diluted 1000 times and the cells were counted using RBC counting chamber. Flowcytometric analysis was done separately using the unstained cells. For this, $300 \mu \mathrm{L}$ of 1000 times diluted endosperm cells preparation was taken and equilibrated with PBS buffer ( $\mathrm{pH} 7.0)$ having 1\% Triton X-100 and then centrifuged at $150 \mathrm{x}$ g to pellet out the nuclei. The pelleted nuclei were suspended in $300 \mu \mathrm{L}$ of PBS buffer and stained with DAPI $\left(5 \mu \mathrm{g} \mathrm{mL}{ }^{-1}\right)$. Following this, the cells were sorted on BD LSR-Fortessa flow cytometer for the density of nuclear staining [51]. For each endosperm cell preparations about 10,000 nuclei were analyzed, and endosperm cell preparations from at least three individual caryopses from control or treated plants, or apical or basal spikelets were considered for counting.

\section{Microscopic analysis of endosperm cells}

The caryopses were dissected out from 12 DAA apical and basal spikelets of BAP-treated and control plants. These were separately soaked overnight in fixing solution made of $50 \mathrm{mM}$ potassium phosphate buffer ( $\mathrm{pH}$ 6.8), 3.7\% paraformaldehyde and $0.2 \%$ picric acid. After washing the fixed endosperm with phosphate buffer, these were dehydrated in gradients of aqueous ethanol and finally dehydrated in absolute alcohol followed by soaking in xylene following standard protocol. The xylene soaked caryopses were then infiltrated with paraffin for sectioning using microtome. The microtome sections, $7 \mu \mathrm{m}$ in thickness, were mounted on glass slides. Paraffin coating was removed from the sections by washing with xylene. Finally, the slides with sections were soaked in DAPI (4',6-diamidino-2-phenylindole) solution (300 $\mathrm{ng} \mathrm{mL}^{-1}$ ) for staining. The stained sections were visualized under fluorescence stereo-microscope for observing the cells and nuclei.

\section{Immuno localisation of cytokinins}

Considering 9 DAA as the period of active metabolism, the apical and basal spikelets collected during this time from the control and BAP-treated OR-1918 cultivar were fixed in Carnoy's solution [50] and processed to get the caryopses as mentioned in the cell counting and flowcytometeric analysis methodology above. Microtome sectioning of these caryopses followed the procedure outlined in the microscopy of endosperms section above. The sections were de-paraffinated by soaking in xylene and then rehydrated by saoking in ethanol solution in water with decreasing percentage of ethanol (100, 95, 70, 30 and $0 \%$ ) for three min each, and then incubated in blocking buffer (0.1X PBS buffer $\mathrm{pH}$ 7.4, $0.25 \% w / v$ BSA, $0.1 \%$ Triton $\mathrm{X}-100,2 \%$ goat serum) at rool temperature with three changes at $10 \mathrm{~min}$ interval. The sections were then immunolabelled for isopentenyladenosine (iPR) and trans-zeatin riboside (tZR) polyclonal antibodies separately by incubating at $4{ }^{\circ} \mathrm{C}$ overnight, and then at room temperature for $1 \mathrm{~h}$. The antibodies were raised in rabit against iPR/tZR conjugated with BSA (Agrisera AB, Sweden). The antibodies used were diluted (1:100) beforehand with blocking buffer. The immuno-reacted sections were washed three times with PBS at 10 min interval and then incubated with secondary antibody (Goat anti-rabbit IgG [H\&L], DYLight 594 conjugated) at room temperature for $2 \mathrm{~h}$. The seconday antibody was diluted 1:200 beforehand with the blocking buffer. After incubation with the secondary antibody the sections were washed with blocking buffer (3 X $10 \mathrm{~min})$ and PBS ( 2 X $10 \mathrm{~min})$ and the whole section was visualized under a fluorescence stereo-microscope.

\section{Results}

Significant differences in yield performance and panicle morphology were observed between the lax- and compactpanicle cultivars, Upahar and OR-1918, respectively (Table 1, Fig. 1). The spikelet numbers per panicle was much more in the compact-panicle OR-1918 than that in the lax-panicle Upahar (Table 1). In contrast, percentage of grain filling was much more in Upahar $(91.60 \%)$ than in OR-1918 (56.23\%). Exogenous application of cytokinin to OR-1918 significantly increased its grain filling percentage (Table 1). Besides, cytokinin treatment also increased the total number of grain on a panicle, the length of panicle, both apical and basal grain weight, and the grain yield per plant as a whole in OR-1918.

Great difference in CKX activity was observed between the two cultivars, the lax-panicle Upahar and compact-panicle OR-1918 (Fig. 2a). The activity of CKX was comparatively less in the apical spikelets than that in the basal spikelets in both compact- and lax-panicle cultivars (Fig. 2a). However, the activity of the enzyme differed highly significantly between the apical and basal spikelets of OR-1918 on all the sampling days, which was not observed in Upahar, except on 12 DAA. The activity of the enzyme was especially much high in the basal spikelets compared with that in the apical spikelets in OR-1918 on 9 DAA compared with that on the other days post-anthesis. This was in contrast to that in Upahar in which the activity of the enzyme increased from 3 DAA to 9 DAA gradually before decreasing slightly on 12 
Table 1 Panicle morphology of OR-1918 and Upahar grown in field and of OR-1918 grown in experimental pots and exposed to $50 \mu \mathrm{M}$ BAP

\begin{tabular}{|c|c|c|c|c|c|c|c|}
\hline & $\begin{array}{l}\text { Panicle } \\
\text { wt. (gm) }\end{array}$ & $\begin{array}{l}\text { Panicle } \\
\text { length }(\mathrm{cm})\end{array}$ & $\begin{array}{l}\text { Spikelets } \\
\text { (number) }\end{array}$ & $\begin{array}{l}\text { Filled } \\
\text { gain (\%) }\end{array}$ & $\begin{array}{l}20 \text { apical } \\
\text { grain wt. (mg) }\end{array}$ & $\begin{array}{l}20 \text { basal } \\
\text { grain wt. (mg) }\end{array}$ & $\begin{array}{l}\text { yield/ } \\
\text { plant (gm) }\end{array}$ \\
\hline \multicolumn{8}{|l|}{ Plants grown in field } \\
\hline OR-1918 & $5.3 \pm 0.2$ & $25.5 \pm 1.5$ & $396 \pm 13.45$ & $56.23 \pm 2.2$ & $430.3 \pm 8.6$ & $244.3 \pm 21.0$ & $46.9 \pm 2.48$ \\
\hline Upahar & $5.6 \pm 0.76$ & $27.06 \pm 0.51$ & $256 \pm 10.0$ & $91.60 \pm 0.56$ & $436.3 \pm 5.5$ & $412.6 \pm 9.0$ & $53.6 \pm 1.97$ \\
\hline ' $t$ ' value at $d f=4$ & $0.73^{\mathrm{ns}}$ & $0.47^{\mathrm{ns}}$ & $9.2^{* * *}$ & $26.9^{* * *}$ & $1.01^{\mathrm{ns}}$ & $12.7^{* * *}$ & $3.6^{*}$ \\
\hline \multicolumn{8}{|l|}{ OR-1918 grown in pots } \\
\hline Control & $5.38 \pm 0.27$ & $24.81 \pm 0.98$ & $403 \pm 22$ & $59.1 \pm 2.8$ & $423 \pm 14$ & $364 \pm 21$ & $47.9 \pm 4.6$ \\
\hline BAP & $6.14 \pm 0.19$ & $26.43 \pm 0.92$ & $479 \pm 25$ & $72.2 \pm 2.3$ & $454 \pm 16$ & $392 \pm 13$ & $69.3 \pm 6.2$ \\
\hline ' $\mathrm{t}$ ' value at $\mathrm{df}=18$ & $7.3^{* * *}$ & $3.82^{* *}$ & $27^{* * *}$ & $5.4^{* * *}$ & $4.6^{* * *}$ & $3.5^{* *}$ & $6.19^{* * *}$ \\
\hline
\end{tabular}

Data are mean \pm SD. The ' $\mathrm{t}$ ' values marked with ${ }^{\prime * \prime}$ ' $* *{ }^{\prime}$ ', or '***' indicate that the difference between concerned two mean values is significant at $p \leq 0.05, p \leq 0.01$ or $p \leq 0.001 * * *$, respectively, while ' $n s^{\prime}$ indicates no significant difference

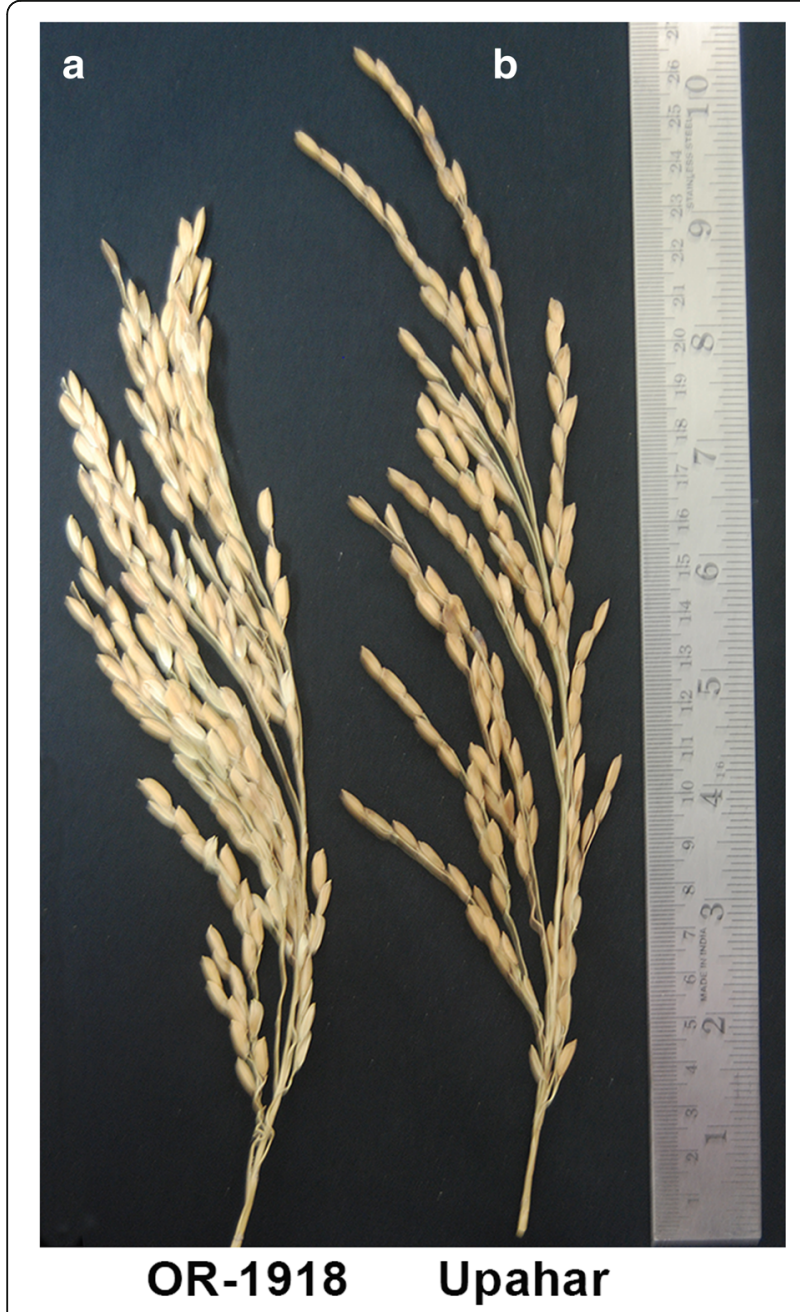

Fig. 1 Representative pictures of compact (a) and lax (b) panicles collected from the plants grown in field
DAA in both apical and basal spikelets. It was also observed that the activity of the enzyme in both apical and basal spikelets of Upahar was much less than that in the basal spikelets of OR-1918 on all the days post-anthesis. Exogenous cytokinin (BAP) application significantly decreased the activity of the enzyme in both apical and basal spikelets of OR-1918 (Fig. 2b). The decrease was, however, more drastic in the basal compared with that in the apical spikelets, especially on 9 and 12 DAAs.

No significant difference in the expression of $C K X$ was observed between the apical and basal spikelets in Upahar for most of the isoforms studied (Fig. 3a). Only CKX9 and CKX3 showed significant difference in expression between the apical and basal spikelets; compared with basal spikelets the expression of $C K X 3$ was significantly higher on 6 DAA and significantly lower on 12 DAA, and that of CKX9 was significantly lower on $6 \mathrm{DAA}$ in the apical spikelets. In contrast, the expression of all the $C K X$ isoforms on most of the days of sampling was significantly lower in the apical than in the basal spikelets in OR-1918, except of CKX4 on 12 DAA when the expression of this isoform was significantly more in the apical than in the basal spikelets. All the isoforms of $C K X$ showed significant decrease in their expression upon cytokinin treatment in the apical spikelets of OR-1918, except $C K X 1$ on 12 DAA when the expression of this isoform increased significantly in response to the cytokinin application (Fig. 3b). In contrast, the basal spikelets showed variable response to the cytokinin application. The expression of CKX3, CKX4 and CKX9 decreased significantly upon cytokinin application on 6 DAA. On 9 DAA sampling the expression of $C K X 1$ and $C K X 9$ was significantly higher in the treated case compared to the control, whereas the expression of $C K X 3$ and $C K X 4$ decreased in response to cytokinin treatment, and the decrease was significant for CKX4. On 12 DAA on the other hand the expression of CKX4 increased significantly together with significant increase in expression of $C K X 1$ and decrease in expression of $C K X 3$ in response to cytokinin application. The expression of $C K X 9$ also increased 

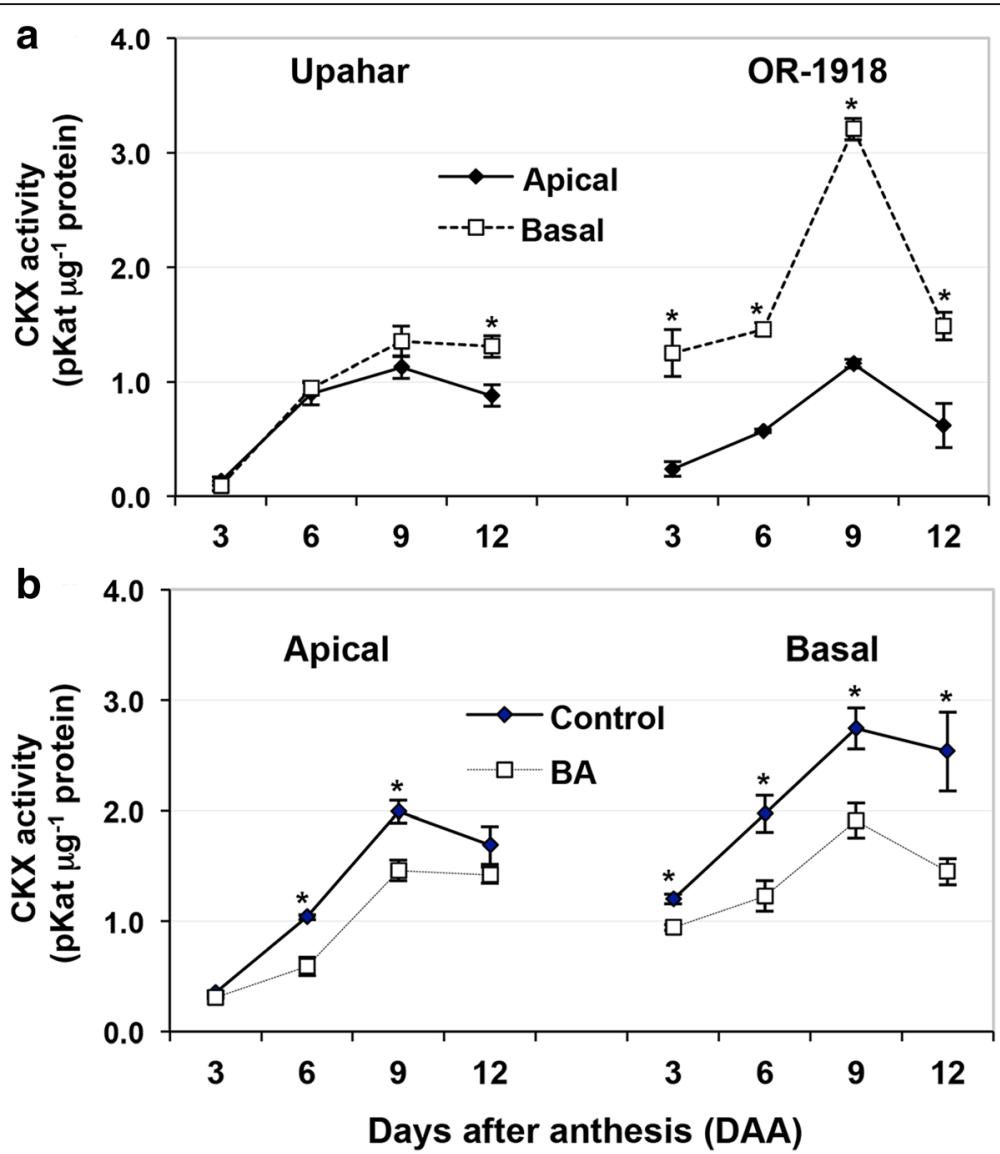

Fig. 2 Cytokinin oxidase (CKX) activity in the spikelets sampled on various days after anthesis (DAA): a) lax-panicle (Upahar) and compact-panicle (OR-1918) rice cultivars were grown in field and comparative analysis of spatio-temporal changes in the enzyme activity was done between the apical and basal spikelets of the individual cultivars; b) the compact-panicle rice cultivar OR-1918 was grown in RCC pots, treated with $50 \mu M$ BAP (6-Benzylaminopurine) through root application before heading and comparative analysis of temporal changes in the enzyme activity was done between apical/basal spikelets from the BAP treated and control (not treated with BAP) plants. Each data point is the mean of three independent estimations \pm SD. The two data points of the same sampling day marked with '*' differ significantly at least at $p \leq 0.05$, as seen by ' $t$ ' test

upon cytokinin application on 12 DAA, similar that on 9 DAA, but the increase was not significant.

All CDKs and cyclins (CYCs) exhibited significantly higher expression in the apical than in the basal spikelets on 6 and 9 DAA in Upahar with CDKB2 showing conspicuously high expression in the apical spikelets on 6 DAA (Fig. 4a). On 12 DAA, the difference in expression of most of them in the apical and basal spikelets was insignificant, except of $C D K B 2$, which showed significantly greater expression in the apical compared with the basal spikelets. In contrast to Upahar, OR-1918 showed very high expression of both $C D K s$ on 6 DAA and of $C D K B 2$, $C Y C B 2$ and $C Y C D 2$ on 9 DAA in the apical than in the basal spikelets. The expression of all cyclins on 6 DAA, CDKA2 and CYCA1 on 9 DAA, and all CDKs and CYCs on 12 DAA differed between the apical and basal spikelets either insignificantly or significantly but with low margin.

Cytokinin treatment significantly increased the expression of $C D K B 2, C Y C A 1$ and $C Y C D 2$ highly in the apical spikelets on 6 DAA, while significantly decreased the expression of $C D K A 2$ and $C Y C B 2$ (Fig. 4b). The expression of all these, except of $C Y C A 1$, on the other hand significantly decreased in the apical spikelets compared to control on 9 DAA. On 12 DAA, however, the expression of all except of CDKB2 increased again in the apical spikelets in response to the cytokinin application. The basal spikelets showed a trend of increase in expression of CDKs and CYCs from 6 to 12 DAA upon cytokinin treatment in contrast to the apical spikelets. The expression of only $C Y C B 2$ on 6 DAA and of only $C D K A 2$ on 9 DAA showed significant decrease in response to cytokinin treatment in the basal spikelets. The expressions of CYCA1 on 6 DAA, of CDKB2 on 9 DAA and of CDKA2, CDKB2, CYCB2 and CYCD2 on 12 DAA on the other hand increased significantly in response to cytokinin treatment in the basal spikelets.

Cytokinin treatment increased the endosperm cell size in both apical and basal spikelets (Fig. 5a, b). The increase in the endosperm cell area was statistically significant in both 


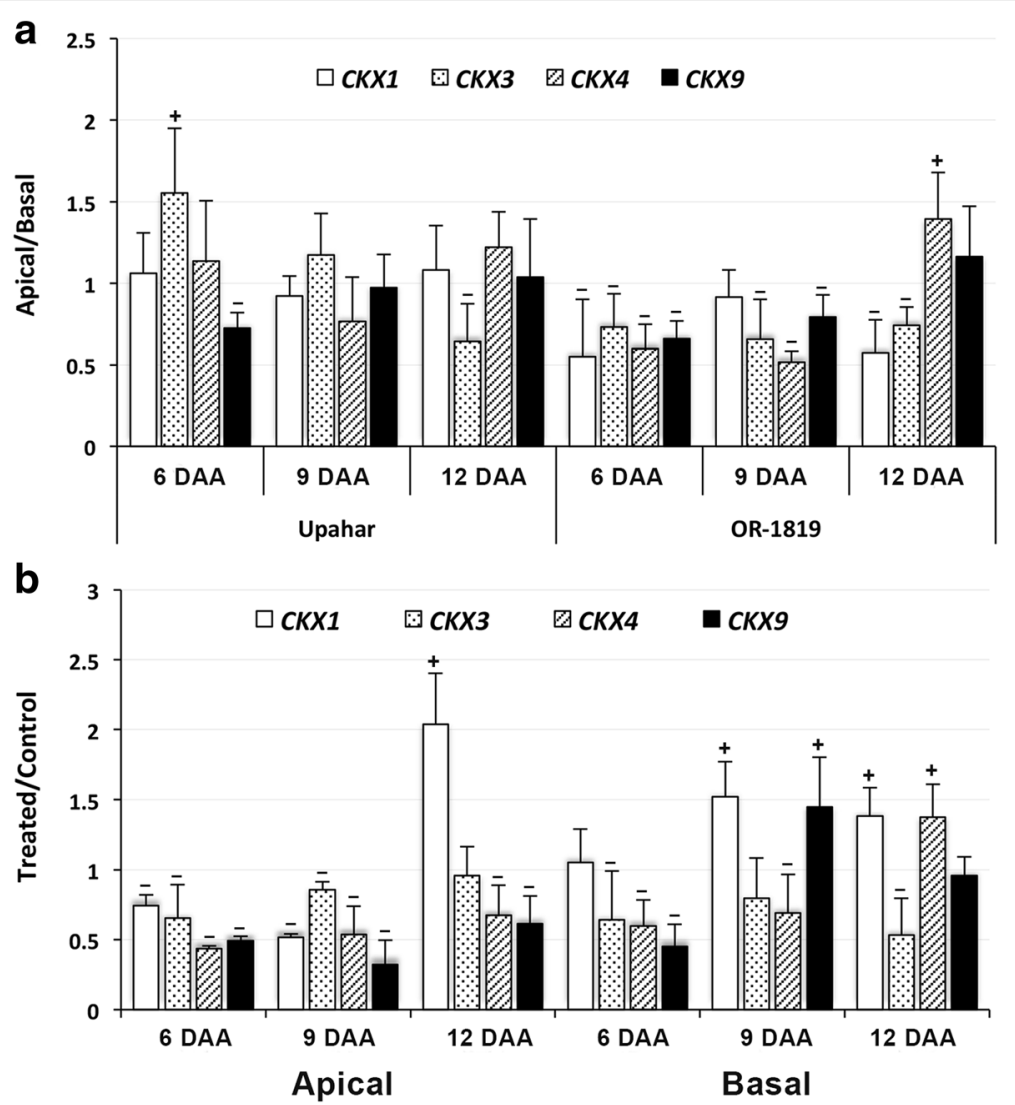

Fig. 3 RT-qPCR results representing relative levels of expression of cytokinin oxidase (CKX) isoforms in the spikelets sampled on various days after anthesis (DAA) from rice cultivars grown in field (a) and in pots (b): a) relative expression in apical spikelets over basal spikelets; b) relative expression in the apical and basal spikelets of the BAP treated plants over that of the control plants. Actin served as the reference control. Other experimental details as in Fig. 2. Plus (+)/minus (-) signs against the vertical bars representing individual genes indicate significantly greater/lesser relative expression of the gene in the apical spikelets compared with the basal ones (a), or in spikelelets sampled from the treated plants

compared with that sampled from the control plants $(\mathbf{b})$ at least at $p \leq 0.05$, as determined by ' $t$ ' test

the cases (Fig. 5b). However, the increase in the endosperm cell size in response to cytokinin treatment was more in the endosperm of the basal than in the endosperm of the apical spikelets compared to the respective control (Fig. 5b). The increase in the cell size in response to the cytokinin application was also accompanied by increase in ploidy level of the nuclei, both in the apical and basal spikelets, as is evident from the flowcytometric data (Fig. 6a). In the apical spikelets the nuclei with ploidy level $3 \mathrm{C}$ and $>3 \mathrm{C}$ were present in nearly equal numbers (Fig. 6a), but the cytokinin treatment created a great shift in their ploidy level to $>3 \mathrm{C}$ (Fig. 6b). In the basal spikelets, the percentage of nuclei with $3 \mathrm{C}$ was much more than that with $>3 \mathrm{C}$ ploidy, but the difference was significantly reduced upon cytokinin treatment that promoted endoreduplication (Fig. 6b).

Among the cytokinin signaling components, the expressions of four response regulators, namely OsRR1, OsRR3, OsRR4 and OsRR6, were recorded (Fig. 7a). They did not show any trend in spatio-temporal variation in either of the cultivars. The expressions of most OsRRs in
Upahar showed insignificant difference whether between apical and basal spikelets or between different days after anthesis except that the expression of OsRR1 was significantly higher in the apical spikelets compared to that in the basal spikelet on 12 DAA, and the reverse was the case for OsRR4 on 6 and 12 DAA and for OsRR3 on 9 DAA. In contrast to Upahar, the expression of OsRR4 and OsRR6 in OR-1918 was significantly greater in the apical over the basal spikelets on 6 and 9 DAA, and the difference became insignificant on 12 DAA. The difference in expression of other OsRRs between the apical and basal spikelets remained insignificant on these days. Cytokinin treatment had an accelerating effect on the expression of most OsRRs (Fig. 7b). It significantly accelerated the expression of OsRR3 on 6 DAA, of OsRR4 on 9 and 12 DAA and of OsRR6 on 6 and 9 DAA in the apical spikelets. Cytokinin application had a greater accelerating effect on the expression of OsRRs in the basal spikelets in comparison to that in the apical spikelets; it significantly accelerated the expression of OsRR3 on 6 

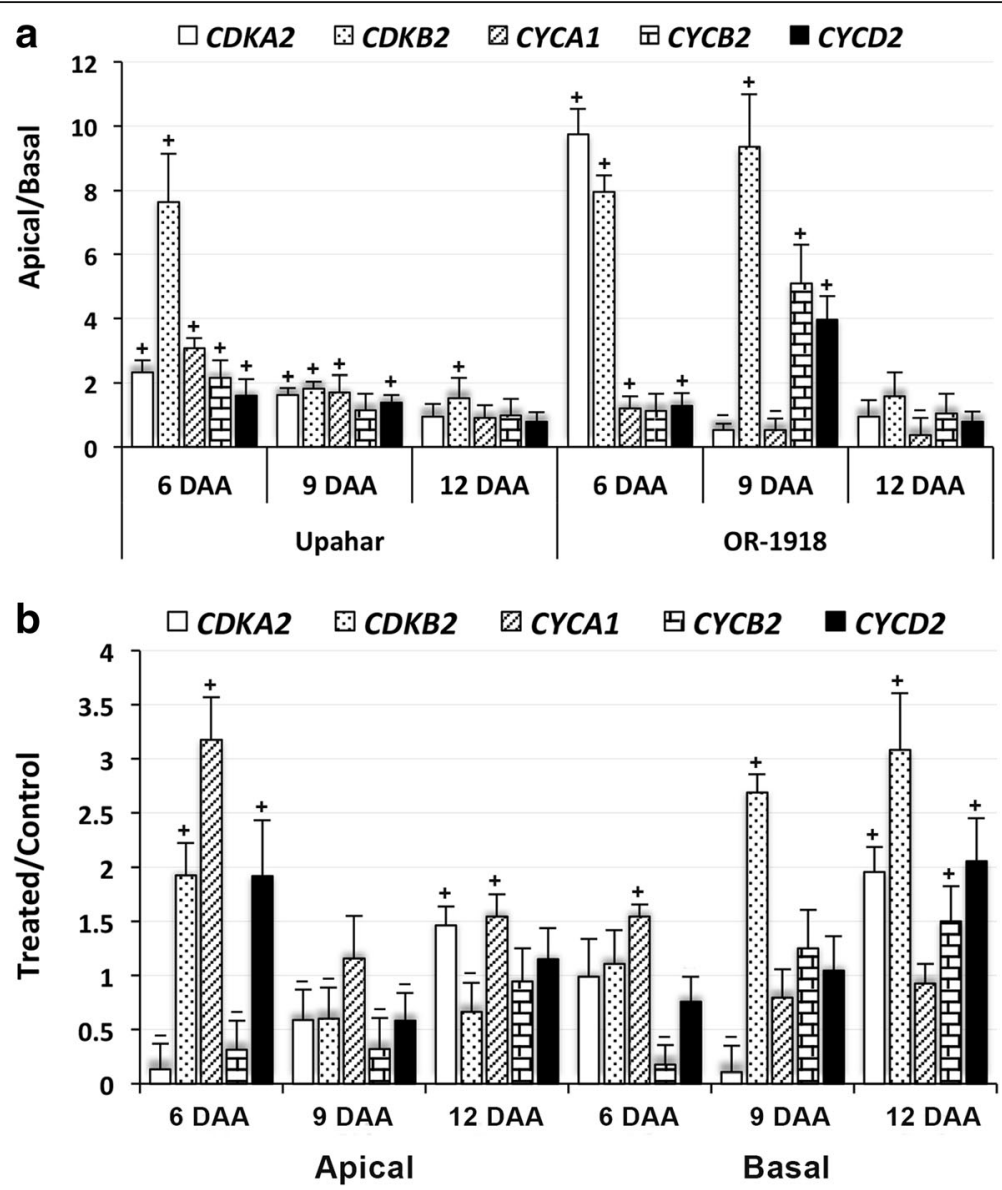

Fig. 4 RT-qPCR results representing relative levels of expression of various cell cycle regulator genes in the spikelets sampled on various days after anthesis (DAA) from rice cultivars grown in field (a) and in pots (b). Other details as in Fig. 3

DAA and 12 DAA, of OsRR6 on 9 and 12 DAA and of OsRR4 on all DAAs in the basal spikelets.

In order to understand the reason of enhancement in grain filling in response to the application of cytokinin, expression study of the main isoform of SUS (sucrose synthase), SUS3, was conducted in the spikelets. SUS3 expressed significantly more in the apical than in the basal spikelets on 6 and 9 DAA, but significantly less in the apical compared with that in the basal spikelets on 12 DAA in both Upahar and OR-1918 (Fig. 8a). Cytokinin treatment increased the expression of SUS3 significantly in the apical as well as in the basal spikelets on all days of sampling (Fig. 8b). However, the influence of the treatment was more on 9 and 12 DAA in apical spikelets and on 6 DAA in the basal spikelets.

Exogenous application of cytokinin to OR-1918 also influenced the endosperm cellular level of the hormone. This is reflected from the increase in the level of $\mathrm{N}^{6}$ isopentenyladenosine (iPR) and trans-zeatin riboside (tZR), and possibly also their bases (iP and $\mathrm{tZ}$ ), as revealed by histochemical analysis of the sections of the caryopses probed with iPR and tZR antibodies, respectively (Fig. 9).
The increase in their level was visible in the caryopses of both the apical and the basal spikelets, but the increase was comparatively more in the caryopses from the basal spikelets compared with that from the apical spikelets. In order to understand the reason of their increase, expression studies of isopentenyl transferases (IPTS) were carried out. Out of the two isoforms of IPT, including IPT9 and IPT10, that were found expressing in the two rice cultivars, IPT9 expressed significantly less in the apical spikelets compared with that in the basal spikelets in Upahar on all the days of sampling, whereas the result was reverse for IPT10, except on 12 DAA (Fig. 10a). In contrast to Upahar, OR-1918 showed significantly greater expression of IPT9 in the apical spikelets compared with the basal ones on 6 and 9 DAA and significantly lower expression of IPT10 in the apical spikelets than that in the basal spikelets on 6 DAA. The expressions of both IPT9 and IPT10 were significantly lower in the apical than in the basal spikelets in OR-1918 on 12 DAA, similar to that in Upahar. Cytokinin application increased the expression of IPT9 significantly in both apical and basal spikelets on all the days of sampling (Fig. 10b). In oppose to IPT9, the expression of IPT10 decreased 


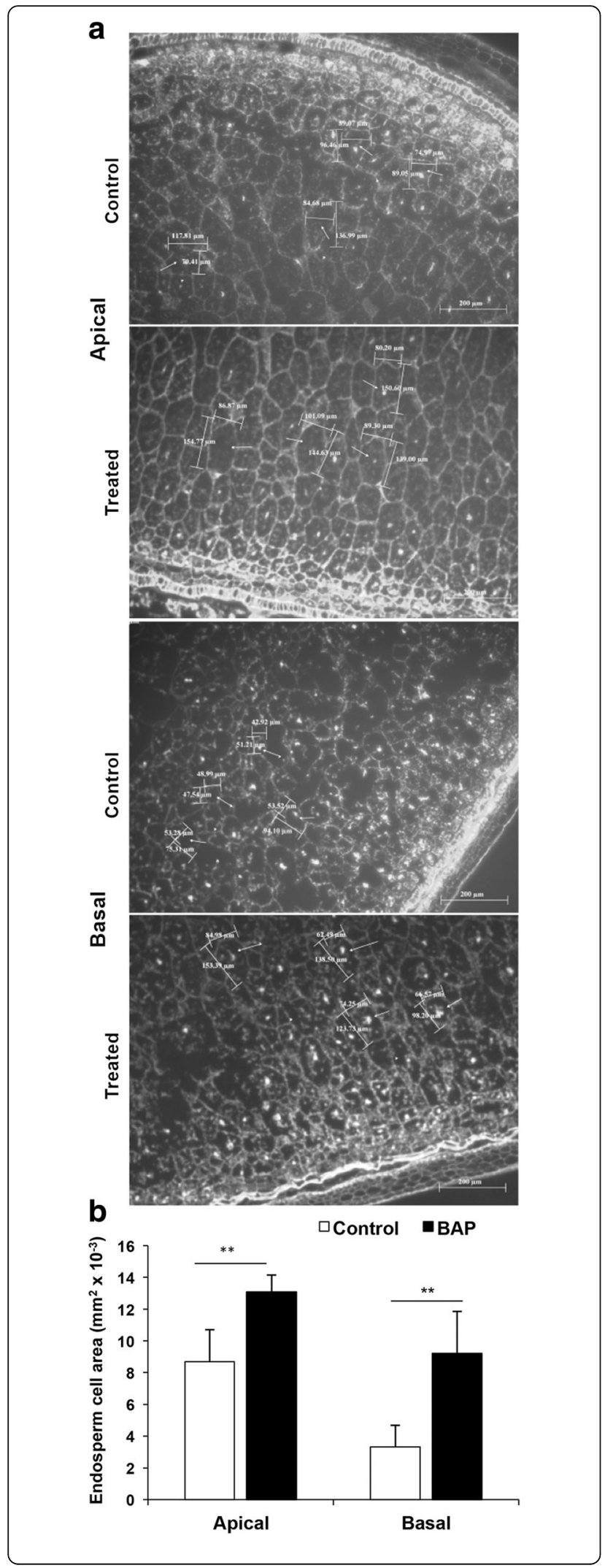

Fig. 5 Visualization of endosperm cell size and cell area. Paraffin embedded caryopses from 12 DAA spikelets were sectioned longitudinally by microtome followed by DAPI staining for comparative visualization of cells and nuclear size (a), and quantification of the endosperm cell area (b) in OR-1918 rice cultivar grown in pots and treated with $50 \mu \mathrm{M}$ BAP through root application. Four cells from each slide were taken for calculation of cells area and represented as mean (vertical bars) $\pm \mathrm{SD}(\mathbf{b})$. The bar pair marked by ${ }^{\prime * * \prime}$ indicates significant difference $(p \leq 0.01)$ in the endosperm cell size of the caryopses from control and BAP treated plants, as revealed by ' $t$ ' test (b)

significantly in both apical and basal spikelets on all the sampling days except on 9 DAA.

\section{Discussion}

It is well established that cytokinins (CKs) have stimulatory effect on cell division in both vegetative and reproductive tissues of plants, as is reflected from their high level in mitotically active areas, like that in the root and shoot meristem [52] and endosperm [44, 45]. So far as reproductive tissue is concerned, there are a few reports of increase in grain weight and endosperm cell numbers in rice upon kinetin application through root treatment $[35,41,43,44]$. The increase in grain filling in the basal spikelets of OR-1918 observed in this study (Table 1) could be a result of stimulatory effect of cytokinin (CK) on the endosperm cell number, which has been reported to bear positive correlation with grain filling and grain weight [53]. CK has also been reported to bear positive relation with the number of spikelets on a panicle in rice [19], as well as in wheat [54], similar to that found in this study (Table 1). Taken together, CK can be considered as an important agent in enhancing the yield potential of rice, as is reflected from its effect on yield value per plant that increased significantly (Table 1 ).

The function of CK in cell proliferation, cell division and differentiation, and shoot and root growth has been well documented [55-57]. The first line of evidence in this direction came from overexpression of CKX, which degrades active CKs, in Nicotiana tabacum that resulted in cytokinin-deficient plants with smaller apical meristems and stunted shoots [28]. The second line of evidence came from identification of QTL for grain number in rice panicle that encode $C K X$ (OsCKX2), the expression of which bears negative correlation with grain number on panicle indicating a positive or stimulatory role of CK on grain number [19]. The increase in the number of grains per panicle upon CK treatment in OR-1918 (Table 1) also supports its role in increasing grain number in rice panicle. However, report on possible influence of $\mathrm{CK}$ on grain filling is scant, although it is well established that CKs level is abundant in immature seeds [58], and prior to grain filling the endosperm cell enters into syncytium phase followed by cellularization [59] and increase in cell numbers [53]. Significantly higher activity level of CKX in the basal spikelets compared 

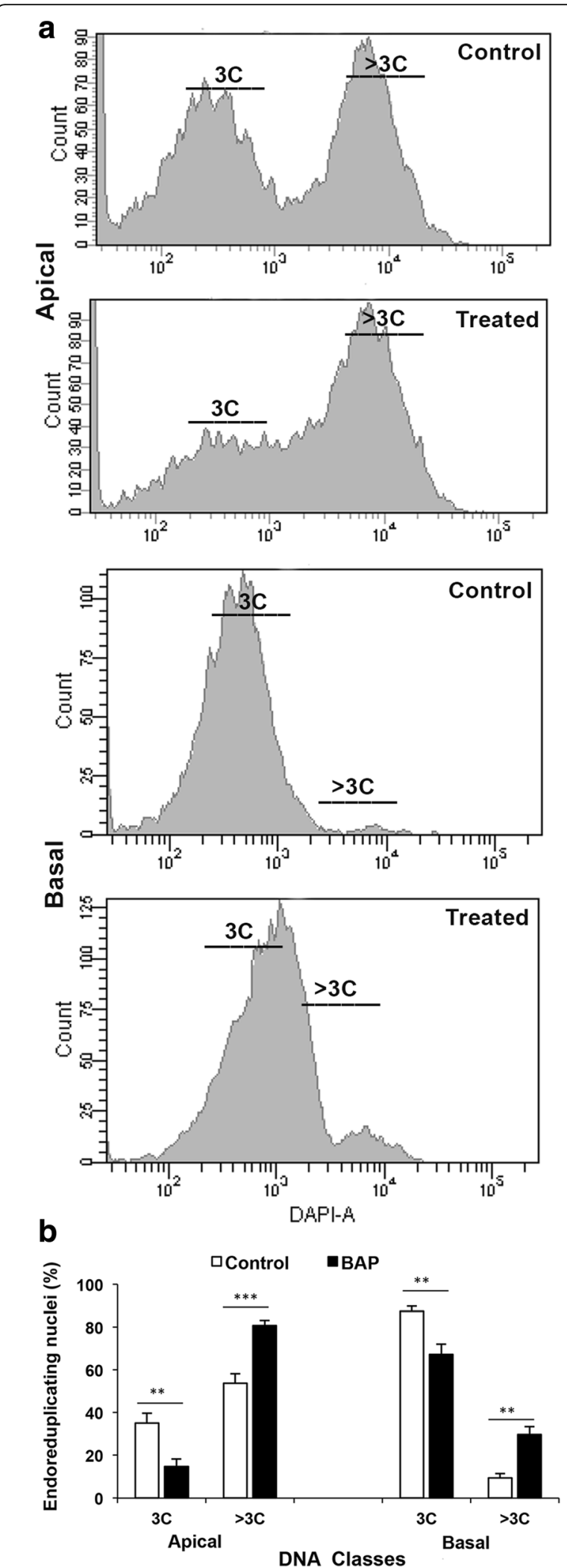

Fig. 6 Flowcytometric analysis of ploidy (DNA class, 3C or > 3C) status of the endosperm nuclei in the apical and basal spikelets sampled on 12 DAA from control and $50 \mu \mathrm{M}$ BAP treated rice cultivar OR-1918 (a), and quantification of the ploidy status of nuclei (b). The endosperm cells of the caryopses released in solution by cellulase treatment were stained with 4',6-diamidino-2-phenylindole (DAPI) for counting the cells (nuclei) representing various ploidy levels (3C and $>3 C$ ). Each panel is representative of three counts from independent endosperm cell preparations. The vertical bars represent mean \pm SD of ploidy status of the nuclei in three independent endosperm cell preparations. The bar pair marked by ${ }^{* * \prime}$ and ${ }^{* * * \prime}$ indicate that the percentage of nuclei representing a ploidy status $(3 \mathrm{C}$ or $>3 \mathrm{C}$ ) in the endosperm cells from control and BAP treated plants differed significantly at $p \leq 0.01$ and $p \leq 0.001$, respectively, as revealed by ' $\mathrm{t}$ ' test (b)

with that in the apical spikelets of the compact-panicle rice cultivar OR-1918 (Fig. 2A) coupled with differential filling of grains in them (Table 1) also indicates that the poor filling of grain in the basal than in the apical spikelets might be related to the level of the hormone in their endosperm cells. A study of CK levels in maize caryopses has in fact revealed highest peak between 8 and 12 DAP (days after pollination), the active period of grain filling, followed by a drop of CK content at 16 DAP [60]. A sharp increase in endogenous CKs has been reported during the phase of active division of endosperm cells in the developing grain in wheat [61]. In general it has been seen that enhancing CK biosynthesis increases yield attributes like pod/seed set and seed development [57]. Besides, it has also been seen that poor grain filling in the basal spikelets in response to drought stress to the plants is associated with a low level of CKs in their endosperm cells when compared to that in the endosperm cells of the apical spikelets in which the grain filling is not affected significantly by the stress [62]. A very high activity of CKX on 9 DAA in the basal spikelets of OR-1918 thus gives an indication that poor filling of grain in them could be as a result of low CK level in comparison to that in the apical spikelets. The present inverse relationship between grain filling and CKX activity is also supported by the observation of an inverse correlation between 1000 grain weight and CKX expression in seven varieties of wheat [63].

The homeostasis of CKs in cells and tissues is maintained not only by its biosynthesis by the enzymes like IPTs (adenosine phosphate isopentenyl transferases) and CYP735A, but also by their degradation by CKX [57] and conversion to inactive $\mathrm{O}$-glucosides and $\mathrm{N}$-glucosides $[31,64]$. The expressions of CKs biosynthesis enzymes are in turn regulated by the phytohormones like $\mathrm{ABA}$ and auxin, and CK itself [56]. Exogenous CK $\left(\mathrm{N}^{6}\right.$ benzylaminopurine, BAP) treatment has been reported to accelerate CKX activity in a few studies involving plant organ and plant culture $[65,66]$. The reason of such cytokinin-induced increase in CKX activity has been 

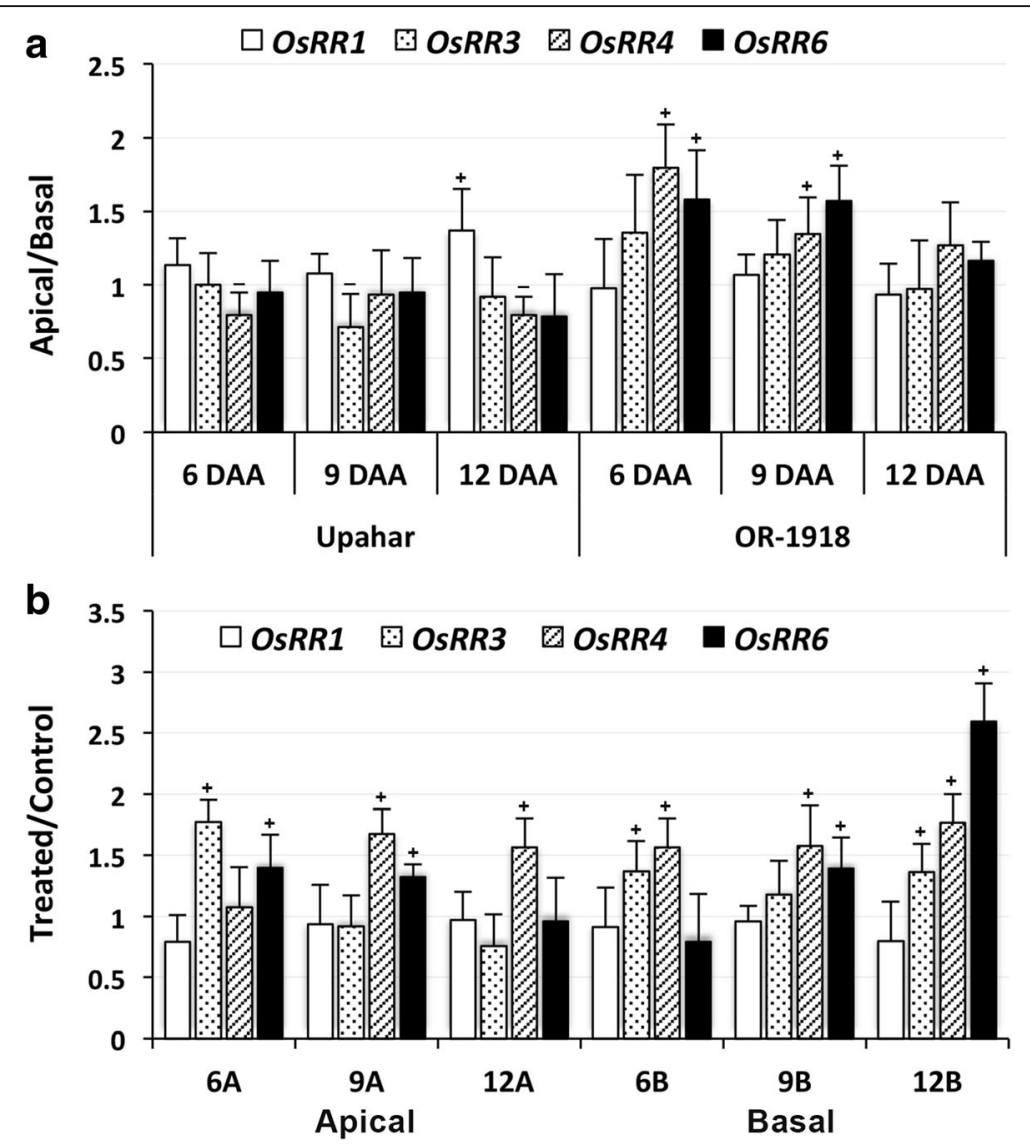

Fig. 7 RT-qPCR results showing relative levels of expression of various response regulator genes (OsRRs) in the spikelets sampled on various days after anthesis (DAA) from rice cultivars grown in field (a) and in pots (b). Other details as in Fig. 3

suggested to be the need of re-establishment and maintenance of intracellular CK homeostasis [67] with the enzyme playing a role as a "detoxifier" of cytokinins in case availability of the hormone is in excess [68]. The exogenous application of CK in the present study, however, resulted in decrease in CKX activity both in apical and basal spikelets (Fig. 2B), suggesting that response to exogenous cytokinin application may be different at the level of tissue (in vitro) than in whole plant (in vivo). The decrease in CKX activity level upon exogenous application of CK observed in the present study supports the maintenance of a high level of the compound in the spikelets of rice plants exposed to the hormone, as reported by others [35, 44], although the study does not agree with the observation of increase in the activity of CKX in response to CK at the level of tissue/plant culture $[65,66]$. The reason of difference in response of CKX in vegetative and reproductive tissues to exogenous application of cytokinin to plants could be because the two tissues might be following different mechanisms for regulation of CK homeostasis in them. Several studies have shown that CKs are synthesized in roots and carried through xylem to the aerial parts, including leaves and reproductive organs with the transpiration system [69-72], and senescence and abscission of leaves is initiated with decrease in synthesis and supply of the hormone from root, the signal for which is sent from shoot to root in some form, the chemical nature of which is so far not clear, when the seeds are in the late stage of development [70, 71, 73-75]. However, synthesis of the hormone de novo in leaves has also been indicated for transportation through phloem to the shoot apex and major sinks lacking xylem connectivity [72, 76]. Because of similar restriction of transport of CKs to the floral organs, maintenance of a low activity of CKX and its proper regulation might be important for maintaining the required level of the hormone in them. This is in conformity with the proposed role of CKX in maintenance of an optimal level of the hormone for growth and/or maintaining the cytokinin signaling system to a required level [28].

Rice genome has 11 isoforms of CKX gene, OsCKX1OsCKX11, of which CKX2, CKX3, CKX4, CKX5, CKX 9 and $C K X 11$ were found to be prominently expressing in rice inflorescence [19]. However, the current study found prominent expression of only four isoforms, including $C K X 1$, $C K X 3, C K X 4$ and $C K X 9$ in the rice spikelets (Fig. 3a). Interestingly, the isoform $C K X 2$, which expressed in flowers and 

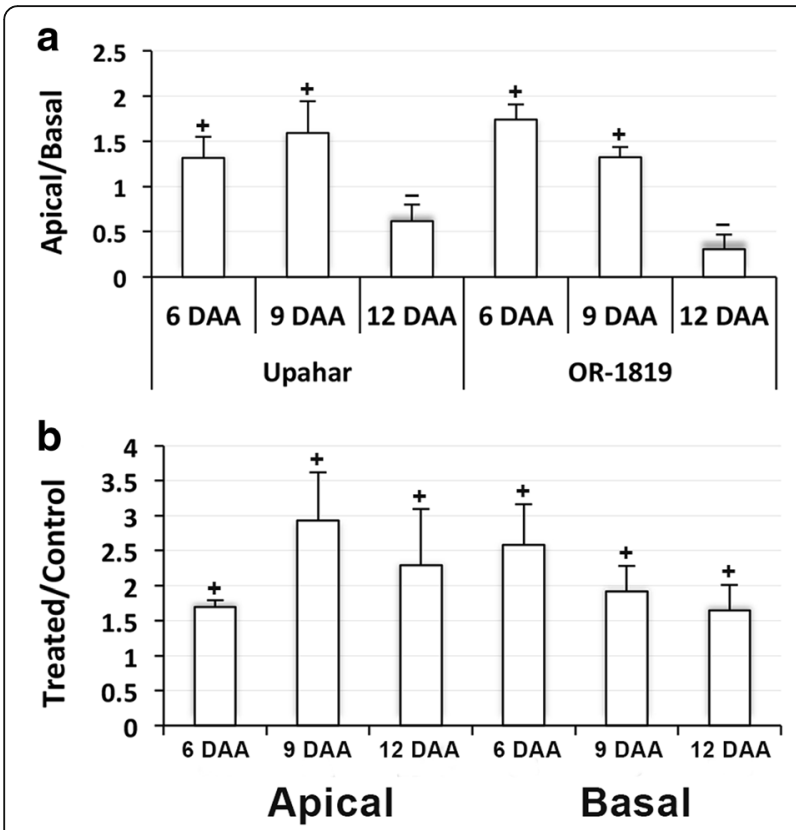

Fig. 8 RT-qPCR results showing relative levels of expression of sucrose synthase3 (SUS3) in the spikelets sampled on various days after anthesis (DAA) from rice cultivars grown in field (a) and in pots (b). Other details as in Fig. 3 inflorescence meristem of O. sativa Japonica cv. Koshihikari bearing less number of spikelets but not in O. sativa Japonica cv. 5150 bearing large number of spikelets, indicating a possible inverse relationship of the enzyme with number of spikelets on a panicle by regulation of the cellular cytokinin level [19], was not found to be expressing either in Upahar bearing less number of spikelets or in OR-1918 bearing large number of spikelets. This suggested that the QTL for grain number, Gn1a, harbouring the candidate gene CKX2 may not be the only factor or gene determining grain numbers in Indica rice cultivars. However, present study does suggest that $C K X$ isoforms like $C K X 1, C K X 3, C K X 4$ and CKXY could be playing important role in Indica cultivars with regard to grain filling. This is because these $C K X$ isoforms had more or less similar expressions in the apical and basal spikelets of the lax-panicle cultivar Upahar (Fig. 3a) together with virtually no difference in the activity of CKX in them (Fig. 2a). Furthermore, these $C K X$ isoforms had significantly lower expressions in the apical than in the basal spikelets of the compact-panicle cultivar OR-1918 on most DAAs (Fig. 3a), which was reflected as significantly low activity of CKX in the apical than in the basal spikelets (Fig. 2a).

The observed downregulation of expression of the CKX isoforms in OR1918 in both apical and basal spikelets upon CK application (Fig. 3b), at least on 6 DAA, the beginning of active phase of endosperm cell division [53], although emphasizes their important role in regulation of the

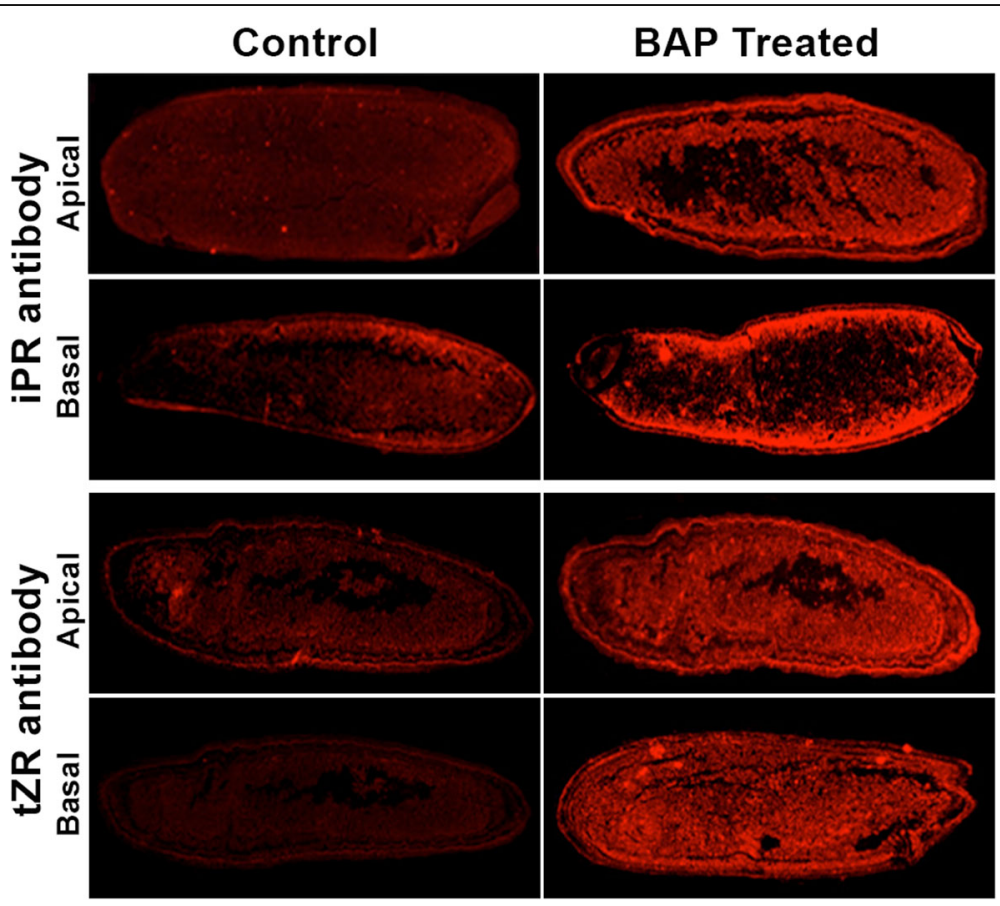

Fig. 9 Immunodetection of trans-zeatin (tZ) riboside (tZR) and $\mathrm{N}^{6}$-( $\Delta^{2}$-isopentenyl)adenine (iP) riboside (iPR) in the endosperm cells of the spikelets sampled on 9 DAA from control and 50 MM BAP treated rice cultivar OR-1918. Immunolabeling for isopentenyladenosine (iPR) and tanszeatin riboside (tZR) was done by polyclonal antibodies raised against iPR/tZR conjugated with BSA, and immunodection followed incubation with secondary antibody. The longitudinal sections of the whole caryopses were observed under a fluorscence streo-microscope 

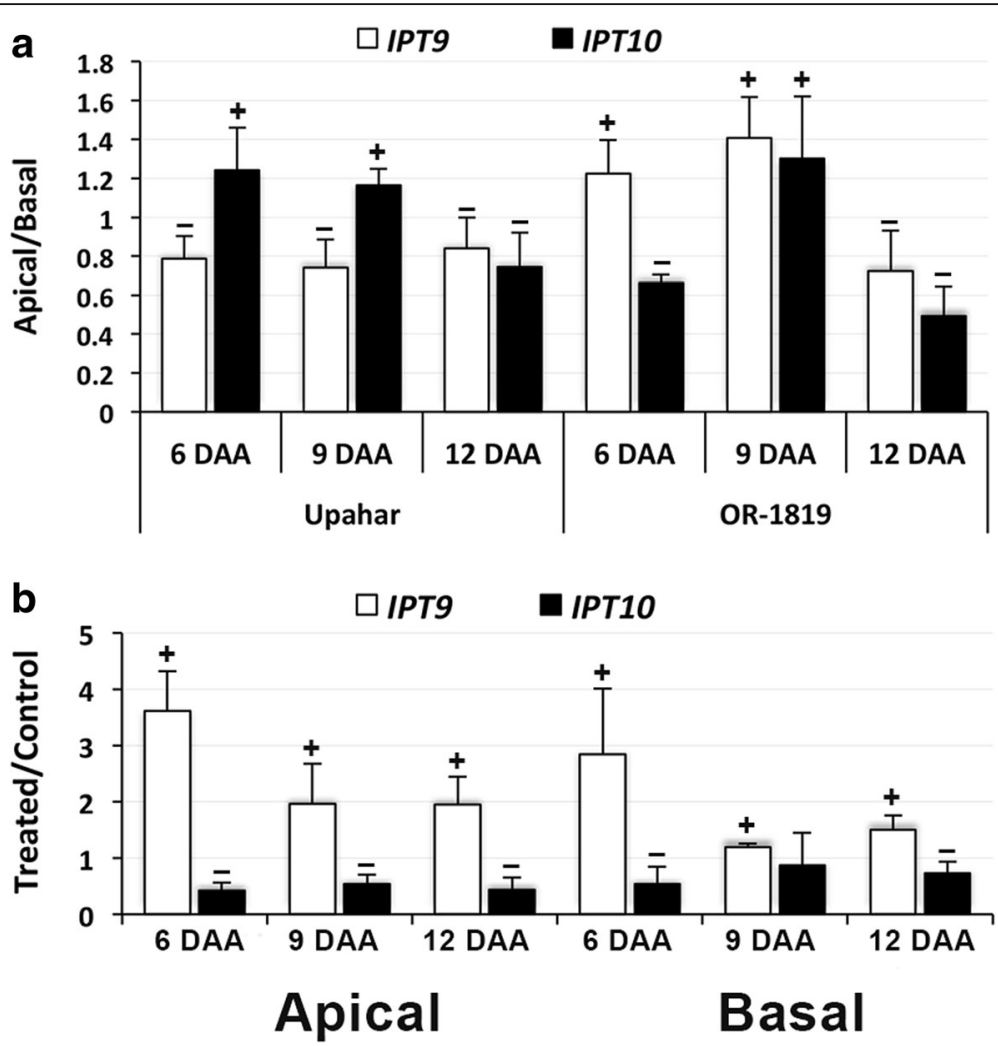

Fig. 10 RT-qPCR results showing relative levels of expression of two isopentenyl transferases (IPTS) in the spikelets sampled on various days after anthesis (DAA) from rice cultivars grown in field (a) and in pots (b). Other details as in Fig. 3

endosperm CK level leading to improvement in grain filling, it is in oppose to the reports of increase in activity of CKX in vegetative tissues in response to exogenous application of the hormone $[65,66]$. Besides, using isolated developing kernels and leaf disc of Zea mays Brugiere et al. [68] have also shown $C K X$ to be inducible by exogenous cytokinins. These observations further suggest that the CK homeostasis mechanism in the reproductive organ in vivo could be different from that operational in the vegetative organs or explants, or in the organs in which the transport of the hormone from root is smooth. Taylor et al. [77] indicated that it is the CKs present in the phloem sap coming from the leaves that enter into the developing inflorescence and fruits rather than that present in xylem coming from roots. In addition, calculation by Letham et al. [78] has shown that only $1.1 \%$ of CKs in seed are derived directly from the xylem. However, it is not yet established what leads to the build up of the required level of CKs for the overall growth of the caryopses to mature seed, although temporal variation of the hormone during endosperm development and seed maturation is well established [35, 44, $62,79,80]$. Upon exogenous application of cytokinin an increase in its level in the endosperm cells may be anticipated through phloem transport, although the same has not been reported so far. An increase in the levels of the hormone in the endosperm cells in fact may also be anticipated based on the available reports that exogenous cytokinin application to rice seedlings induces expression of most of OsRRs [46], and that overexpression of OsRR6 in rice leads to downregulation of OsCKX4 and OsCKXS [75]. However, the mechanism of maintenance of cellular CK homeostasis mediated through type-A RRs regulated expression of $C K X$ is yet to be fully understood, particularly in developing endosperm cells. This is because there are 13 OsRRs in rice and the regulatory role of each of them is yet to be characterized, although it is established through transgenic experiments that type-A RRs act as negative regulator of CK signaling [81], and overexpression of type-A RRs, like ARR4, ARR5, ARR6 and ARR7 represses the promoter activity of ARR6 [82]. Significant acceleration in expression of $C K X 1$ and $C K X 9$ on 9 DAA and of $C K X 1$ and $C K X 4$ on 12 DAA in response to the exogenous CK application might be because of above transcription regulatory mechanism of the $C K X$ genes not yet understood fully. Irrespective of the factor(s) regulating the expression of individual CKX isoforms, it is, however, clearly established that a low CKX activity favours grain yield, both in terms of grain number and grain weight, as silencing of $H \nu C K X 1$ in barley increased grain yield of the plant [29], similar to that obtained with mutation of $C K X 2$ in rice [19]. Our 
findings in the present study (Fig. 2a, b) are in conformity to these reports $[19,29]$.

It is well established that grain filling process is preceded by endoreduplication of endosperm cells regulated by cell cycle regulators [83], and CK plays important role in cell division, proliferation and differentiation [55-57]. A few reports have demonstrated that $\mathrm{CK}$ induces expression of CYCD3 $[84,85]$, and that activation of CDKA by type-D cyclins (CYCDs) promotes G1-S transition in plants leading to active cell division [86]. Type-B cyclins on the other are the cyclin class that is involved in G2-M phase transition through interaction with CDKA and CDKB $[52,86]$. Although G2-M phase transition is regulated in plant by CK application, as evidenced by several experiments on cell lines $[87,88]$, the mechanism is not yet fully clear, except that cytokinin can be replaced by the transgene $C D K$ Tyr phosphatase Cdc25 for supporting and initiating mitosis [89]. The possible role of cyclins and CDKs in cell division is clearly visible in the present study also, as OR1918 had a very high level of expression of CYCA1, $C Y C B 2$ and $C D K B 2$ in the apical spikelets compared with that in the basal spikelets on 9 DAA (Fig. 4A) representing initiation of highly active phase of endosperm cell division and corroborating with the fact that the apical spikelets had better grain filling than the basal spikelets (Table 1). On the other hand in Upahar that shows no difference in grain filling between apical and basal spikelets (Table 1), the spatial difference in the expression of these cell cycle regulators on 9 DAA was not much pronounced, although significant (Fig. 4a). Hence, it is possible that highly significant accelerating effect of $\mathrm{CK}$ treatment on the expression of CDKs and CYCs in apical and basal spikelets, particularly on 12 DAA in the basal spikelets (Fig. 4b), might be causing an enhanced division of endosperm cell in them during the period leading to significant increase in grain filling (Table 1).

Grain filling is although positively related to endosperm cell division [53, 54], it is also a result of increased anabolism symbolized by increase in cell size and supported by endoreduplication of the nuclei, a phenomenon widely reported for storage tissues and other tissues undergoing rapid differentiation and expansion in plants like that in root nodules, cotyledons and pericarp [90-93]. The increase in grain filling in OR-1918 upon CK application in the present study also appears to be a result of increase in cell size and endoreduplication (Fig. 5a, b, 6a, b). It has been suggested that endoreduplication, which triggers anabolism that follows increase in cell size, is a result of check of G2-M phase transition. This blockage results in re-entry of the cells to $\mathrm{S}$ phase leading to increase in their ploidy level. The check of G2-M transition is although suggested to be primarily a result of decrease in cyclin B level [83], it is not supported in this study since the expression of cyclin $B$ significantly increased in both apical and basal spikelets upon cytokinin treatment, particularly on 12 DAA (Fig. 4b), the approximate start time point of endoreduplication process. The process of endoreduplication thus could be more complicated than simply to be a result of depletion of the cyclin B level in the cells, particularly in context to the role of CK, or plant hormone in general. This is reflected from the findings like 1) CKs inhibit endocytic recycling of PIN1, a member of PIN family of auxin efflux carriers that promotes degradation of auxin in the vacuole, leading to increase in its cellular level and thereby promoting endoreduplication [88, 94, 95], 2) CKs promotes expression of CCS52A1 that stimulate degradation of mitotic cyclins, which promotes endoreduplication [96], and 3) endogenous oscillation of CKs level accompanies progress of cell cycle, but their exogenous application that decreases the amplitude of fluctuation of the hormone retards cell cycle progression, promoting endoreduplication [97]. In general it is said that CKs at lower concentrations activates mitosis and cell division, but at higher concentrations favour endoreduplication [86].

Cytokinin response in rice is mediated by twocomponent systems involving histidine kinase membrane bound receptors, OHKs, and multistep phosphorelay signaling components comprising of histidine-contaning phosphotransmitter (OHP) and response regulators (RR), which are categorized into type-A, OsRR, and type-B, ORR [27]. CKs are perceived by histidine kinases generating signal that is transferred in the form of phosphoryl group through OHP in the cytoplasm to the response regulators in nucleus $[98,99]$. Five histidine kinases, OHK1$O H K 5$, two histidine phosophotransmitter, OHP1 an $O H P 2$, thirteen type-A $R R, O s R R 1-O s R R 13$, and five typeB RR, ORR1-ORR5 genes have been identified in rice through database search of Japonica rice using the sequence information of such genes from Arabidopsis and maize [27]. Expressions of all these genes, except of OsRR1-3 and OsRR5-7, were checked in different tissues of rice, and were found to be expressing [27]. However, the current study was restricted to see the expression pattern of only OsRRs of the two component signaling system. This is because genes that code for HK, HP and type-B RR have been reported not to be responsive to CK [75]. Besides, it has also been seen that CK regulates the expression of type-A $R R$ in addition to a large number of other genes $[75,100,101]$. In fact, type-A RRs have been reported to be the primary $\mathrm{CK}$ response genes since these are induced by the hormone even in the absence of protein synthesis de novo [46]. Besides, overexpression of a type-A RR member, OsRR6, in rice abolishes shoot regeneration, suggesting a negative regulator function of $O s R R$ in CK signaling [75]. The role of type-A $R R$ as negative regulator in CK signaling has also been demonstrated in Arabidopsis by overexpression of ARR8 and ARR15 in the plant $[82,102]$. However, specific role of the individual 
OsRRs is yet to be studied. Besides, there occurs cultivarspecific differences in expression of the OsRRs; while Jain et al. [46] reported expression of all the $R R$ isoforms in flower of the Indica cultivar Pusa Basmati, Ito and Kurata [27] did not find OsRR1-3 and OsRR5-7 to be expressing in Japonica cultivar Nipponbare. The current study is in agreement to this, as only OsRR1, OsRR3, OsRR4 and OsRR6 were found to be mainly expressing in the spikelets of OR-1918 and Upahar (Fig. 7a). The other isoforms although expressed, but their expression was either very low or these expressed only on the initial days of anthesis (data not shown).

The comparative expression study of the four OsRR isoforms in apical and basal spikelets of Upahar and OR1918 (Fig. 7a) suggested that a high expression level of $R R s$ might favour grain filling. This is because the expressions of at least OsRR4 and OsRR6 in OR-1918 showing spatial difference in grain filling were more in the apical than in the basal spikelets (Fig. 7a), which might be a result of a greater phosphorylation status of the pool of type-B RR in the presence of a higher level of CKs in the apical than in the basal spikelets (Fig. 9); it is well established that upon getting phosphorylated by histidinecontaining phosphotransmitter, type-B RRs activate transcription of the primary cytokinin response genes, including some type-A RRs [82, 101, 103]. Comparatively poor expression of OsRR4 and OsRR6 in the basal spikelets than in the apical ones could be the reason of a higher activity and expression of $C K X$ in the basal spikelets compared with that in the apical spikelets of OR-1918 (Figs. 2a, 3a) leading to differential grain filling in them; transcriptional repressor function of certain type-A RRs has been reported [82]. Overexpression of at least two type-A RRs, $A R R 7$ and OsRR6, have been found to lead to downregulation of CKX in Arabidopsis and rice, respectively [75, 104]. In addition, it is well established that type-A RRs are negative regulators of CK responses [81, 82]. However, the factors that determines differential expression of type-A RR in tissues of the same plant, the apical and basal spikelets in the present case, in absence of exogenous application of $\mathrm{CK}$ is not yet established. The tissue/organ based differential expression of type-A RRs is reflected in the present study even in response to exogenous application of CK with the basal spikelets showing greater response in terms of induced expression of OsRRs than the apical spikelets (Fig. 7b). Besides, the response of the individual RRs, including OsRR3, OsRR4 and OsRR6, varied depending on the days after anthesis with OsRR1 not showing any response (Fig. 7b). Although the reason of spatio-temporal differential response of these RRs to CK application may not be explained, the results do indicate that increase in the expression level of OsRR3, OsRR4 and OsRR6 might be the cause of improvement in grain filling in OR-1918, particularly in the basal spikelets, brought about by decrease in expression of $C K X$ (Fig. 3b). Improvement in grain filling induced by cytokinin application is also reflected from upregulation of SUS3 expression, the major isoform of sucrose synthase that drives the initial reaction leading to conversion of sucrose to starch, in the basal spikelets of OR-1918 (Fig. 8b). However, so far no relationship of the cellular CK level or cytokinin signaling with the expression of the enzymes involved in grain filling has been indicated. It could be that cytokinin-induced increase in cell size (Fig. 5a, b) and endoreduplication in the endosperm cells of both apical and basal spikelets of OR-1918 (Fig. 6a, b) might be driving better expression of SUS3, and also of other enzymes involved in grain filling.

It is established that the metabolic control of CKs is highly complex, as is reflected from the numbers of genes whose expression is influenced by them [75, 100, 105, 106], and this is further complicated by their structural diversities and the biosynthesis and degradation mechanisms involved in maintenance of their cellular homeostasis [56, 75]. Besides, it is not yet clear what determines the structural variants of CK to be present in cell and in what proportion, which are also species-specific [56]. Exogenous application of synthetic hormone BAP results in great variation in cellular level of various CKs in tobacco and wheat $[54,66]$, the reason of which is not yet explained. Increase in the levels of isopentenyladenosine (iPR) and trans-zeatin riboside (tZR) in the caryopses in response to exogenous BAP application (Fig. 9) is in agreement with the reports available. The increase in the level of iPR and tZR in response to exogenous application is also supported from acceleration in expression of IPT9 in both apical and basal spikelets, comparatively more in the apical than in the basal spikelets (Fig. 10b), corresponding to increase in the level of iPR and tZR (Fig. 9). In contrast, the expression of IPT10, the other isoform of the enzyme that expressed under control condition, declined in response to BAP application (Fig. 10b), suggesting CK inducibility of IPT9. Besides, a greater expression of IPT9 in the apical than in the basal spikelets of the compact-panicle cultivar OR-1918 (Fig. 10a), coupled with increase in its expression in response to BAP application in both apical and basal spikelets (Fig. 10b) and improvement in grain filling (Table 1) suggested it to be an important factor in determining grain filling in rice.

\section{Conclusions}

The study thus indicated that CK metabolism could be of much importance in the process concerned with grain filling in rice. It is well reflected from a high activity level of CKX and a greater expression of the CKX isoforms in the poorly filled basal spikelets compared with that in the well filled apical spikelets of the compact-panicle rice cultivar OR-1918. Furthermore, exogenous application of CK improves grain filling in the spikelets significantly, and this is accompanied by significant decrease in the 
levels of expression of most of the CKX isoforms, both in apical and basal spikelets. The findings not only support the reported negative relationship of CKX activity with grain number [19], but also explain observation of high CK level in immature seeds [58, 60], as both the processes precede an enhanced cellularization, which CK supports $[55,56]$. At the level of maintaining cellular homeostasis of cytokinin, it may be said that the hormone acts as repressor of $C K X$ expression through typeA RRs, as evidenced by transgenic experiments [81, 82], although the process is far more complex [35, 62, 65, 66, $68,77]$. Moreover, the level of CK in the caryopses might also be modulated through regulation of expression of $I P T s$, particularly of IPT9, as its expression level increased significantly in response to BAP application. The study finally suggested that grain filling in rice can be improved through biotechnological intervention, which may be achieved by seeds-specific overexpression of type-A RRs, like OsRR4 and OsRR6 that showed significantly high expression in the apical than in the basal spikelets, or more specifically by seed-specific overexpression of IPT9 that showed significant increase in response to exogenous application of CK.

\section{Additional file}

Additional file 1: Nucleotide sequences of the genes considered in this study and the primers used for their expression studies. (XLSX $34 \mathrm{~kb}$ )

\section{Acknowledgements \\ The authors thank Director, Institute of Life Sciences (ILS) for allowing the experiments to be conducted in the Institute. The authors also thank the Director, NRRI, Cuttack for allowing to using the field facility of the institute for the work. The authors thankfully acknowledge the technical suggestions extended by Dr. Santibhusan Senapati of ILS on microtomy. Sabindra Kumar Samal and Paritosh Nath helped in cell size determination and flowcytometry experiment, respectively. Prof. S. R. Das of OUAT, Bhubaneswar provided seeds of OR-1918 and Upahar. Finally, the authors are thankful to Prof. S. K. Panda, Assam Central University, Silchar for help in language editing.}

\section{Funding}

This study was carried out with the help of financial assistance under Young Scientist project (NO. SB/YS/LS-73/2013) sanctioned by the Department of Science and Technology, Govt. of India.

\section{Availability of data and materials}

The nucleotide sequences of the genes considered in this study are available in Additional file 1 along with the primer sequences.

\section{Authors' contributions}

BBP and BPS designed the experiments. SKD and LB raised and maintained the plants in field and guided the work on yield related parameters. BBP and SS executed the experiments in laboratory. BPS and BBP analyzed the data. BPS wrote the manuscript. BBP and SKD helped in final preparation of the manuscript. All authors approved the final version of the manuscript.

\section{Authors' information}

BPS is a senior faculty in ILS in Plant Biotechnology and Crop Improvement group. SKD and LB are Principal Scientists in NRRI in Crop Improvement Division.

Ethics approval and consent to participate Not applicable.

\section{Competing interests}

The authors declare that they have no competing interests.

\section{Publisher's Note}

Springer Nature remains neutral with regard to jurisdictional claims in published maps and institutional affiliations.

\section{Author details}

${ }^{1}$ Institute of Life Sciences, Bhubaneswar, Odisha, India. ${ }^{2}$ National Rice Research Institute, Cuttack, Odisha, India.

Received: 24 July 2017 Accepted: 3 April 2018

Published online: 21 May 2018

\section{References}

1. Fageria N. Yield physiology of rice. J Plant Nutr. 2007;30:843-79.

2. Peng S, Laza CR, Visperas RM, Khush GS, Virk P, and Zhu D. "Rice: Progress in Breaking the Yield Ceiling", in. Proceedings of the 4th International Crop Science Congress, 26 Sep-1Oct, Brisbane. 2004. Australia.www.cropscience. org.au/icsc2004/pdf/982_pengs.pdf

3. Horie T, Shiraiwa T, Homma K, Katsura K, Maeda S, Yoshida H. Can yields of lowland rice resume the increases that they showed in the 1980s. Plant Prod Sci. 2005:8:259-74.

4. UN.World population prospects: the 2012 revision. New York: UN, Department of Economic and Social Affairs, Population Division, Working Paper No. ESA/P/WP.228; 2013. http://esa.un.org/unpd/wpp/publications/ Files/WPP2012_HIGHLIGHTS.pdf

5. Gupta MD, Engelman R, Levy J, Luchsinger G, Merrick T. and Rosen JEY. "Big numbers, big chanllenges, big possibilities", in State of the world population, ed. R. Kollodge. (New York: UNFPA, United Nations Population Fund), 1-12.http://www.unfpa.org/sites/default/files/pub-pdf/EN-SWOP14Report FINAL-web.pdf. 2014

6. Zhang Q. Strategies for developing green super rice. Proc Nat Acad Sci. 2007:104:16402-9.

7. IRRI. Rice Almanac. Los Baños, Philippines: International Rice Research Institute. 1997.

8. Yang J, Zhang J. Grain-filling problem in 'super' rice. J Exp Bot. 2010;61:1-5.

9. Khush G. Productivity improvements in rice. Nature Rev. 2003:61:S114-6.

10. Peng S, Cassman KG, Virmani SS, Sheehy J, Khush GS. Yield potential trends of tropical since the release of IR8 and its challenge of increasing rice yield potential. Crop Sci. 1999;39:1552-9.

11. Cheng S, Cao L, Zhuang J, Chen S, Zhan X, Fan Y, et al. Super hybrid rice breeding in China: achievements and prospects. J Integr Plant Biol. 2007;49: 805-10.

12. Peng S, Khush GS, Virk P, Tang Q, Zou Y. Progress in ideotype breeding to increase rice yield potential. Field Crops Res. 2008;108:32-8.

13. Yang J, Peng S, Zhang Z, Wang Z, Visperas RM, Grain ZQ. Dry matter yields and partitioning of assimilates in japonica/indica hybrids. Crop Sci. 2002a;42: 766-72

14. Ao H, Wang S, Zou Y, Peng S, Tang Q, Fang Y, et al. Study on yield stability and dry matter characteristics of super hybrid rice. ScientiaAgriculturaSinica. 2008:41:1927-36.

15. Sekhar S, Panda BB, Mohapatra T, Das K, Shaw BP, Kariali E, Mohapatra PK. Spikelet-specific variation in ethylene production and constitutive expression of ethylene receptors and signal transducers during grain filling of compact- and lax-panicle rice (Oryza sativa) cultivars. J Plant Physiol. 2015;179:21-34

16. Panda BB, Badoghar AK, Das K, Panigrahi R, Kariali E, Das SR, et al. Compact panicle architecture is detrimental for growth as well as sucrose synthase activity of developing rice kernels. Func Plant Biol. 2015;42:875-87.

17. Xing Y, Zhang Q. Genetic and molecular bases of rice yield. Annu Rev Plant Biol. 2010;61:421-42

18. Mohapatra PK, Panigrahi R, Turner NC. Physiology of spikelet development on the rice panicle. is manipulation of apical dominance crucial for grain yield improvement? Adv Agron. 2011;110:333-59.

19. Ashikari M, Sakakibara H, Lin S, Yamamoto T, Takashi T, Nishimura A, et al. Cytokinin oxidase regulates rice grain production. Sci. 2005:309:741-5.

20. Li M, Li X, Zhou Z, Wu P, Fang M, Pan X, et al. Reassessment of the four yield-related genes Gn1a, DEP1, GS3, and IPA1 in Rice using a CRISPR/Cas9 system. Front Plant Sci. 2016;7:377. https://doi.org/10.3389/fpls.2016.00377. 
21. Mok MC. "Cytokinins and plant development- an overview"' in Cytokinins, ed. Mok DWS, Mok MC (Boca Raton, Fl:CRC Press). 155-166.1994.

22. Skoog F, Miller CO. Chemical regulation of growth and organ formation in plant tissues cultured in vitro. Symp Soc Exp Biol. 1957;11:118-31.

23. Haberer $\mathrm{G}$, Kieber JJ. Cytokinins. New insights into a classic phytohormone Plant Physiol. 2002;128:354-62.

24. Werner T, Schmülling T. Cytokinin action in plant development. Curr Opin Plant Biol. 2009;12:527-38.

25. Mok DW, Mok MC. Cytokinin metabolism and action. Annu Rev Plant Physiol Plant Mol Biol. 2001;52:89-118.

26. Davies PJ. Plant hormones: biosynthesis, signal transduction, action. The Netherlands: Kluwer Academic Press; 2004

27. Ito $\mathrm{Y}$, Kurata N. Identification and characterization of cytokinin-signalling gene families in rice. Gene. 2006;382:57-65.

28. Werner T, Motyka V, Strnad M, Schmulling T. 2001. Regulation of plant growth by cytokinin. Proc. Nat. Acad. Sci. USA. 2001;98:10487-92.

29. Zalewski W, Galuszka P, Gasparis S, Orczyk W, Nadolska-Orczyk A. Silencing of the HvCKX1 gene decreases the cytokinin oxidase/ dehydrogenase level in barley and leads to higher plant productivity. J Exp Bot. 2010;61:1839-51.

30. Motyka V, Faiss M, Strnad M, Kamínek M, Schmülling T. Changes in cytokinin content and cytokinin oxidase activity in response to derepression of ipt gene transcription in transgenic tobacco calli and plants. Plant Physiol. 1996;112:1035-43.

31. Blagoeva E, Dobrev PI, Malbeck J, Motyka V, Gaudinova A, Van`kova R. Effect of exogenous cytokinins, auxins and adenine on cytokinin N-glucosylation and cytokinin oxidase/dehydrogenase activity in de-rooted radish seedlings. Plant Growth Regul. 2004;44:15-23.

32. Kato T. Effect of spikelet removal on grain filling of Akenohoshi, a rice cultivar with numerous spikelets in a panicle. J Agric Sci. 2004;142:177-81.

33. Peng T, Lv Q, Zhao YF, Sun HZ, Han YC. Du et al. superior grains determined by grain weight are not fully correlated with the flowering order in rice. J Integr Agric. 2015;14:847-55.

34. Marcelis LFM. Sink strength as a determinant of dry matter partitioning in the whole plant. J of Exp Bot. 1996;47:1281-91.

35. Zhang $\mathrm{H}$, Tan $\mathrm{G}$, Yang L, Yang J, Zhang J, Zhao B. Hormones in the grains and roots in relation to post-anthesis development of inferior and superior spikelets in japonica/indica hybrid rice. Plant Physiol Biochem. 2009;47:195-204.

36. Kuanar SR, Panigrahi R, Kariali E, Mohapatra PK. Apoplasmic assimilates and grain growth of contrasting rice cultivars differing in grain dry mass and size. Plant Growth Regul. 2010;61:135-51.

37. Yang J, Zhang J, Wang Z, Liu K, Wang P. Post-anthesis development of inferior and superior spikelets in rice in relation to abscisic acid and ethylene. J Exp Bot. 2006;57:149-60.

38. Eeuwens CJ, Seed SWW. Pod wall development in Pisum sativum L. in relation to extracted and applied hormones. J Exp Bot. 1975;26:1-14.

39. Lur HS, Setter TL. Role of auxin in maize endosperm development: timing of nuclear DNA endoreduplication, zein expression, and cytokinins. Plant Physiol. 1993;103:73-280.

40. Saha S, Nagar PK, Sircar PK. Cytokinin concentration gradient in the developing grains and upper leaves of rice (Oryza sativa) during grain filling. Can J Bot. 1986;64:2068-72.

41. Dietrich JT, Kaminek M, Blevins DG, Reinbott TM, Morris RO. Changes in cytokinins and cytokinin oxidase activity in developing maize kernels and effects of exogenous cytokinin on kernel development. Plant Physiol Biochem. 1995;33:327-36.

42. Morris RD, Blevins DG, Dietrich JT, Durly RC, Gelvin SB, ed G. Cytokinins in plant pathogenic bacteria and developing cereal grains. Aust J Plant Physiol. 1993;20:621-37.

43. Jones RJ, Schreiber BMN, McNeil KJ, Brenner ML, Faxon G. Cytokinin levels and oxidase activity during maize kernel development. In: Kaminek M, Mok BWS, Zazimalova E, editors. Pysiology and biochemistry of Cytokinins in plants. The Hague, The Netherlands: SPB Academic Publishing; 1992. p. 235-9.

44. Yang J, Zhang J, Huang Z, Wang Z, Zhu Q, Liu L. Correlation of cytokinin levels in the endosperms and roots with cell number and cell division activity during endosperm development in rice. Ann Bot. 2002b;90:369-77.

45. Yang J, Peng S, Visperas RM, Sanico AL, Zhu Q, Grain GS. Filling pattern and cytokinin content in the grains and roots of rice plants. Plant Growth Regul. 2000;30:261-70

46. Jain M, Tyagi AK, Khurana JP. Molecular characterization and differential expression of cytokinin-responsive type-a response regulators in rice (Oryza sativa). BMC Plant Biol. 2006;6:1. https://doi.org/10.1186/1471-2229-6-1. 2006.
47. Frébort I, Šebela M, Galuszka P, Werner T, Schmülling T, Peč P. Cytokinin oxidase/cytokinin dehydrogenase assay: optimized procedures and applications. Anal Biochem. 2002;306:1-7.

48. Bradford M. A rapid and sensitive method for quantitation of microgram quantities of protein utilizing the principle of protein-dye-binding. Anal Biochem. 1976;72:248-54.

49. Pfaffl MW. A new mathematical model for relative quantification in real-time RT-PCR. Nucleic Acid Res. 2001;29(9):e45.

50. Singh BK, Jenner CF. A modified method for determination of cell number in wheat endosperm. Plant Sci Lett. 1982;26:273-8.

51. Brown SC, Bergounioux C, Tallet S, Marie D. Flow cytometry of nuclei for ploidy and cell cycle analysis. In: A laboratory guide for cellular and molecular plant biology, eds. I. Negrutiu, G. Gharti-Chhetri (Basel:Birkhäuser); 1991. p. 326-45

52. D'Agostino IB, Kieber JJ. Molecular mechanisms of cytokinin action. Curr Opin Plant Biol. 1999;2:359-64.

53. Panda BB, Kairali E, Panigrahi R, Mohapatra PK. High ethylene production slackens seed filling in compact-panicle rice cultivar. Plant Growth Regul. 2009:58:141-51.

54. Yang D, Li Y, Shi Y, Cui Z, Luo Y, Zheng M, et al. Exogenous cytokinins increase grain yield of winter wheat cultivars by improving stay-green characteristics under heat stress. PLoS One. 2016;11(5):e0155437. doi.org/10. 1371/journal.pone.0155437

55. Kyozuka J. Control of shoot and root meristem function by cytokinin. Curr Opin Plant Biol. 2007;10:442-6.

56. Sakakibara H. Cytokinins: activity, biosynthesis, and translocation. Annu Rev Plant Biol. 2006:57:431-49.

57. Jameson PE, Song J. Cytokinin: a key driver of seed yield. J Exp Bot. 2016;67: 593-606.

58. Letham DS. Cytokinins as phytohormones - sites of biosynthesis, translocation, and function of translocated cytokinin. In: Mok DWS, Mok MC, editors. Cytokinins: chemistry, activity, and function. Boca Raton, FL. USA: CRC Press; 1994. p. 57-80.

59. Mizutani M, Naganuma T, Tsutsumi K, Saitoh Y. The syncytium-specific expression of the Orysa;KRP3 CDK inhibitor: implication of its involvement in the cell cycle control in the rice (Oryza sativa L.) syncytial endosperm. J Exp Bot. 2010;61:791-8.

60. Rijavec T, Li QB, Dermastia M, Chourey PS. Cytokinins and their possible role in seed size and seed mass determination in maize. In: Montanaro G, Dichio $B$, editors. Advances in selected plant physiology aspects. Shanghai: In Tech; 2012. p. 293-308

61. Jameson PE, McWha JA, Cytokinins WGJ. Changes in their activity during the development of grains of wheat (Triticumaestivum L.). Z Pflanzenphysiol. 1982:106:27-36.

62. Zhang H, Chen T, Wang Z, Yang J, Zhang J. Involvement of cytokinins in the grain filling of rice under alternate wetting and drying irrigation. J Exp Bot. 2010:61:3719-33.

63. Zhang L, Zhao Y, Gao L, Zhao G, Zhou R, Zhang B, et al. TaCKX6-D1, the ortholog of rice OsCKX2, is associated with grain weight in hexaploid wheat. New Phytol. 2012;195:574-84.

64. Hou B, Lim E-K, Higgins GS, Bowles DJ. N-Glucosylation of Cytokinins by glycosyltransferases of Arabidopsis thaliana. J Biol Chem. 2004;279: 47822-32.

65. Auer CA, Motyka V, Brezinova' A, Kamınek M. Endogenous cytokinin accumulation and cytokinin oxidase activity during shoot organogenesis of Petuniahybrida. Physiol Plant. 1999;105:141-7.

66. Motyka V, Vankova R, Capkova V, Petrasek J, Kaminek M, Schmülling T. Cytokinin-induced upregulation of cytokinin oxidase activity in tobacco includes changes in enzyme glycosylation and secretion. Physiol Plant. 2003; 117:11-21.

67. Kamínek M, Motyka V, Vaňková R. Regulation of cytokinin content in plant cells. Physiol Plant. 1997;101:689-700.

68. Brugiere N, Jiao S, Hantke S, Zinselmeier C, Roessler JA, Niu X, et al. Cytokinin oxidase gene expression in maize is localized to the vasculature, and is induced by cytokinins, abscisic acid, and abiotic stress. Plant Physiol. 2003:132:1228-40.

69. van Staden J, Cook EL, Nooden LD. Cytokinins and senescence. In: Senescence and aging in plants, eds. L.D. Nooden, a.C. Leopold (San Diego: academic press); 1988. p. 281-328.

70. Nooden LD, Singh S, Letham DS. Correlation of xylem sap cytokinin levels with monocarpic senescence in soybean. Plant Physiol. 1990;93:33-9. 
71. Carlson DR, Dyer DJ, Cotterman CD, Durley RC. The physiological basis for cytokinin induced increases in pod set in IX93-100 soybeans. Plant Physiol. 1987;84:233-9.

72. Kamboj JS, Blake PS, Baker DA. Cytokinins in the vascular saps of Ricinus communis. Plant Growth Reg. 1998;25:123-6.

73. Heindl JC, Carlson DR, Brun WA, Brenner ML. Ontogenetic variation of four cytokinins in soybean root pressure exudate. Plant Physiol. 1982;70:1619-25.

74. Bernier G, Havelange A, Houssa C, Petitjean, Lejeune P. Physiological signals that induce flowering. Plant Cell 1993;5:1147-1155.

75. Hirose N, Makita N, Kojima M, Kamada-Nobusada T, Sakakibara H. Overexpression of a type-a response regulator alters rice morphology and cytokinin metabolism. Plant Cell Physiol. 2007;48:523-39.

76. Palni LMS, Nandi SK, Singh S, Letham DS. An overview of cytokinin biosynthesis. In: Pharis RP, Rood SB, editors. In plant growth substances. Berlin: Springer-Verlag; 1990. p. 258-66.

77. Taylor JS, Thompson B, Pate JS, Atkins CA, Pharis RP. Cytokinins in the phloem sap of white lupin (Lupinus albus L.). Plant Physiol. 1990;94:1714-20.

78. Letham DS, Parker CW, Zhang R, Singh S, Upadhyaya MN, Dart PJ, Palni LMS. Xylem-translocated cytokinin: metabolism and function. In: Plant growth substances, eds. R.P. Pharis, S.B. rood S.B. Berlin, Heidelberg: Springer; 1988. p. 275-81.

79. Yang J, Zhang J, Wang Z, Zhu Q, Wang W. Hormonal changes in the grains of rice subjected to water stress during grain filling. Plant Physiol. 2001;127: 315-23.

80. Yang JC, Zhang JH, Wang ZQ, Zhu QS. Hormones in the grains in relation to sink strength and post anthesis development of spikelets in rice. Plant Growth Regul. 2003;41:185-19.

81. To JPC, Haberer G, Ferreira FJ, Deruere J, Mason MG, Schaller GE, et al. Typea Arabidopsis response regulators are partially redundant negative regulators of cytokinin signaling. Plant Cell. 2004;16:658-71.

82. Hwang I, Sheen J. Two-component circuitry in Arabidopsis cytokinin signal transduction. Nature. 2001:413:383-9.

83. Panda BB, Badoghar AK, Sekhar S, Shaw BP, Mohapatra PK. 1-MCP treatment enhanced expression of genes controlling endosperm cell division and starch biosynthesis for improvement of grain filling in a dense-panicle rice cultivar. Plant Sci. 2016:246:11-25.

84. Riou-Khamlichi C, Huntley R, Jacqmard A, Murray JA. Cytokinin activation of Arabidopsis cell division through a D-type cyclin. Science. 1999:283:1541-4.

85. Scofield S, Dewitte W, Nieuwland J, Murray JAH. The Arabidopsis homeobox gene SHOOT MERISTEMLESS has cellular and meristem-organisational roles with differential requirements for cytokinin and CYCD3 activity. Plant J. 2013:75:53-66.

86. Schaller GE, Street IH, Cytokinin KJJ. The cell cycle. Curr Opin Plant Biol. 2014:21:7-15.

87. John PCL, Zhang K, Dong C, Diederich L, Wightman F. p34cdc2 related proteins in control of cell cycle progression, the switch be- tween division and differentiation in tissue development and stimulation of division by auxin and cytokinin. Aust J Plant Physiol. 1993;20:503-26.

88. Valente P, Tao W, Verbelen JP. Auxins and cytokinins control DNA replication and deduplication in single cells of tobacco. Plant Sci. 1998;134:207-15.

89. Zhang K, Diederich $L$, John PCL. The cytokinin requirement for cell division in cultured nicotianaplumbaginifolia cells can be satisfied by yeast Cdc25 protein tyrosine phosphatase: implications for mechanisms of cytokinin response and plant development. Plant Physiol. 2005;137:308-16.

90. Lukaszewska E, Virden R, Sliwinska. Hormonal control of endoreduplication in sugar beet (Beta vulgaris L.) seedlings growing in vitro. Plant Biol 2012;14: 216-222.

91. Foucher F, Kondorosi E. Cell cycle regulation in the course of nodule organogenesis in Medicago. Plant Mol Biol. 2000;43:773-86.

92. Bergervoet JHW, Verhoeven HA, Gilissen LJW, Bino RJ. High amounts of nuclear DNA in tomato (Lycopersicon esculentum mill.) pericarp. Plant Sci. 1996:116:141-5.

93. Marciniak KDNA. Endoreplication level in endosperm and in cotyledons during seed development in three dicotyledonous species. Acta Soc Bot Pol. 1991;60:273-84.

94. Atif RM, Boulisset F, Conreux C, Thomposon R, Ochatt SJ. In vitro auxin treatment promotes cell division and delays endoreduplication in developing seeds of the model legume species Medicago truncatula. Physiol Plant. 2013:148:549-59.

95. Marhavy' P, Bielach A, Abas L, Abuzeineh A, Duclercq J, Tanaka H, et al. Cytokinin modulates endocytic trafficking of PIN1 auxin efflux carrier to control plant organogenesis. Dev Cell. 2011;21:796-804.
96. Takahashi N, Kajihara T, Okamura C, Kim Y, Katagiri Y. Okushima et al. Cytokinins control endocycle onset by promoting the expression of an APC/C activator in Arabidopsis roots. Curr Biol. 2013;23:1812-7.

97. Hartig K, Beck E. Endogenous cytokinin oscillations control cell cycle progression of tobacco BY-2 cells. Plant Biol. 2005;7:33-40.

98. Perception KT. Signal transduction of cytokinins. Annu Rev Plant Biol. 2003; 54:605-27.

99. Hwang I, Sheen J. Two-component circuitry in Arabidopsis cytokinin signal transduction. Nature (London). 2001:413:383-9.

100. Rashotte AM, Carson SDB, To JPC, Kieber JJ. Expression profiling of cytokinin action in Arabidopsis. Plant Physiol. 2003:132:1998-2011.

101. D'Agostino IB, Deruere J, Kieber JJ. Characterization of the response of the Arabidopsis response regulator gene family to cytokinin. Plant Physiol. 2000; 124:1706-17.

102. Osakabe Y, Miyata S, Urao T, Seki M, Shinozaki K, Yamaguchi-Shinozaki K. Overexpression of Arabidopsis response regulators, ARR4/ATRR1/IBC7 and ARR8/ATRR3, alters cytokinin responses differentially in the shoot and in callus formation. Biochem Biophys Res Commun. 2002;293:806-15.

103. Sakai H, Honma T, Aoyama T, Sato S, Kato T, Tabata S Oka A. ARR1, a transcription factor for genes immediately responsive to cytokinins. Science. 2001;294:1519-21.

104. Lee DJ, Park JY, Ku SJ, Ha YM, Kim S, Kim MD, et al. Genome-wide expression profiling of Arabidopsis response regulator (ARR7) overexpression in cytokinin response. Mol Gen Genomics. 2007;277:115-37.

105. Brenner WG, Romanov GA, Köllmer I, Bürkle L, Schmülling T. Immediateearly and delayed cytokinin response genes of Arabidopsis thaliana identified by genome-wide expression profiling reveal novel cytokininsensitive processes and suggest cytokinin action through transcriptional cascades. Plant J. 2005;44:314-33.

106. Kiba T, Naitou T, Koizumi N, Yamashino T, Sakakibara H, Mizuno T. Combinatorial microarray analysis revealing Arabidopsis genes implicated in cytokinin responses through the his $\rightarrow$ asp phosphorelay circuitry. Plant Cell Physiol. 2005:46:339-55.

\section{Ready to submit your research? Choose BMC and benefit from:}

- fast, convenient online submission

- thorough peer review by experienced researchers in your field

- rapid publication on acceptance

- support for research data, including large and complex data types

- gold Open Access which fosters wider collaboration and increased citations

- maximum visibility for your research: over $100 \mathrm{M}$ website views per year

At BMC, research is always in progress.

Learn more biomedcentral.com/submissions 